\title{
NOBLE GASES IN THE EARTH'S MANTLE
}

\author{
K. A. Farley and E. Neroda \\ Division of Geological and Planetary Sciences, MS 170-25, California Institute of \\ Technology, Pasadena, California 91125; e-mail: farley@gps.caltech.edu
}

KEY WORDS: mantle evolution, atmosphere formation, mantle geochemistry, planetary outgassing, radiogenic isotopes

\begin{abstract}
Noble gas isotopic ratios in mantle-derived samples require variability in the timeintegrated ratio of volatile to lithophile elements in the Earth. Documentation of mantle ${ }^{3} \mathrm{He} /{ }^{4} \mathrm{He}$ variability is becoming increasingly complete, but for the heavier noble gases, the picture is still partly clouded by the effects of atmospheric contamination of mantle samples. Nevertheless, clear variations in mantle $\mathrm{Ne}$, $\mathrm{Ar}$, and $\mathrm{Xe}$ isotopic ratios exist, are apparently correlated with ${ }^{3} \mathrm{He} /{ }^{4} \mathrm{He}$, and may be the product of varying degrees of mantle degassing. However, uncertainties in noble gas geochemical behavior and several conflicting observations leave open other possibilities. Recent Ne isotopic data are particularly important because they require that the atmosphere has not been closed to exchange with space. Derivation of much of the atmosphere from a source other than degassing of the mantle is a strong possibility that complicates efforts to model the geochemical evolution of the Earth.
\end{abstract}

\section{INTRODUCTION}

The isotopic and elemental abundances of the noble gases in terrestrial materials provide unique insights to the degassing history of the Earth, the origin of the atmosphere, and the chemical heterogeneity of the mantle. These elements comprise a family of chemically inert species whose physical properties vary systematically, making their geochemical behavior easier to predict than that of the major volatiles carbon and nitrogen. In addition, many noble gas isotopes are produced by nuclear processes within the Earth, yielding measurable isotopic variations that convey information on the timing and mechanism of the geochemical evolution of the planet. 
The composition of the atmosphere is distinct from that of the solar nebula, requiring its derivation from a more chemically evolved source, possibly the solid Earth (Brown 1952). The discovery that the nonradiogenic isotope ${ }^{3} \mathrm{He}$ emanates from mid-ocean ridges provided the first demonstration that terrestrial degassing is both incomplete and ongoing (Clarke et al 1969; see also Mamyrin et al 1969). Because the mantle is not completely devoid of volatiles, degassing and atmosphere formation processes are likely recorded by the composition of mantle volatiles. For more than 25 years, investigators have attempted to understand these processes through noble gas isotopic analyses of mantle-derived rocks.

Recent progress in this field has arisen from expanded sample coverage and improvements in analytical techniques that now permit high quality isotopic analyses of all of the noble gases on a single aliquot. In addition, serious problems associated with sample quality that compromised many early analyses are now recognized and can sometimes be corrected for. Here we present a summary of the noble gas data in mantle samples and discuss its implications. For some isotopic systems, a richly detailed picture has emerged, while for others, significant uncertainties remain. Some of these data seem to confirm early ideas regarding planetary differentiation, but others are puzzling and potentially require profound reinterpretations of our understanding of mantle and atmosphere evolution and the relationship between the two.

\section{GEOCHEMISTRY AND ISOTOPIC SYSTEMATICS}

The noble gases are chemically inert, and their abundances within Earth materials are modified only by radioactive decay and physical processes such as melting and vapor-phase transport. During mantle melting, the noble gases likely partition into the melt, with this tendency decreasing with atomic number. For He, the olivine/basaltic melt $K_{d}$ is probably $<0.008$ (Marty \& Lussiez 1993, Hiyagon \& Ozima 1986). Partition coefficients for the heavier noble gases are more poorly known. For example, $K_{d}$ estimates for Ar range from $<0.003$ to 7, and for Xe from $<0.3$ to as high as 90 (Hiyagon \& Ozima 1986, Broadhurst et al 1992, Marty \& Lussiez 1993). Although the lowest $K_{d}$ s are consistent with a major role for magmatic outgassing in the formation of the atmosphere, the highest values would imply that magmatic processes are an inefficient mechanism by which to outgas the Earth. These unsatisfyingly discrepant results likely arise from the difficulty of measuring very small quantities of the noble gases dissolved in silicates that may also carry adsorbed and inclusion-borne components. How the uncharged and comparatively large noble gas atoms are housed in mineral matrices is unclear. Defects may play a prominent role. If so, standard laboratory techniques may be inappropriate 
for estimating partition coefficients relevant to mantle conditions (Carroll \& Draper 1994). Despite these ambiguities, most workers assume the noble gases behave moderately to highly incompatibly during mantle melting.

Noble gas solubilities in silicate liquids generally follow Henry's law, with solubility decreasing by $\sim 50 x$ from He to Xe (Jambon et al 1986, Lux 1987). The noble gases are all much less soluble than water; the solubility of Ar in basaltic melts is comparable to that of $\mathrm{CO}_{2}$. In an ascending magma the noble gases will partition strongly into the first-formed vapor phase, usually nearly pure $\mathrm{CO}_{2}$, with the heavier gases preferentially enriched in the vapor. Because most basalts erupted on the Earth's surface are thought to be variably outgassed of $\mathrm{CO}_{2}$ (Gerlach 1989), the concentration and relative abundances of the noble gases may be greatly modified during magmatism. For that reason we will not discuss noble gas abundances here; see Ozima (1994) for a recent review of this subject.

The major utility of the noble gases lies in their isotopic compositions, which are modified by a variety of nuclear processes, including simple radioactive decay and nucleogenic reactions involving interactions of $\alpha$ particles and neutrons (both ultimately derived from $U$ and $T h$ decay) with target nuclei. Some of the important nuclear processes and isotopic ratios for mantle geochemistry are listed in Table 1 (see also Ozima 1994). All of the noble gases have at least one radiogenic isotope, but the isotopic effects on krypton are expected (and observed) to be negligible (Ozima 1994). Variations in most noble gas isotopic ratios reflect heterogeneity in the time-integrated ratio of a radioactive parent to a nonradiogenic isotope of the daughter element. The most significant processes responsible for parent/daughter fractionation are thought to be

Table 1 Noble gas isotopic ratios, nuclear processes, and time scales relevant for the mantle

\begin{tabular}{clll}
\hline \hline Isotopic ratio & \multicolumn{1}{c}{ Nuclear process } & Half-life (Ma) & Comment \\
\hline${ }^{3} \mathrm{He} /{ }^{4} \mathrm{He}$ & ${ }^{238} \mathrm{U} \rightarrow 8 \alpha+{ }^{206} \mathrm{~Pb}$ & 4,468 & \\
& ${ }^{235} \mathrm{U} \rightarrow 7 \alpha+{ }^{207} \mathrm{~Pb}$ & 703.8 & \\
& ${ }^{232} \mathrm{Th} \rightarrow 6 \alpha+{ }^{208} \mathrm{~Pb}$ & 14,010 & \\
${ }^{21} \mathrm{Ne} /{ }^{22} \mathrm{Ne}$ & ${ }^{18} \mathrm{O}(\alpha, \mathrm{n})^{21} \mathrm{Ne}$ & See $\mathrm{U}, \mathrm{Th}$ & Nucleogenic reactions \\
& ${ }^{24} \mathrm{Mg}(\mathrm{n}, \alpha){ }^{21} \mathrm{Ne}$ & & from U and Th decay \\
${ }^{40} \mathrm{Ar} /{ }^{36} \mathrm{Ar}$ & ${ }^{40} \mathrm{~K} \rightarrow 0.1048{ }^{40} \mathrm{Ar}$ & 1,251 & Branched decay \\
${ }^{129} \mathrm{Xe} /{ }^{130} \mathrm{Xe}$ & ${ }^{129} \mathrm{I} \rightarrow{ }^{129} \mathrm{Xe}$ & 0.016 & Extinct parent \\
${ }^{136} \mathrm{Xe} /{ }^{130} \mathrm{Xe}$ & ${ }^{238} \mathrm{U}$ fission & 4,468 & \\
& ${ }^{244} \mathrm{Pu}$ fission & 0.082 & Extinct parent
\end{tabular}

Note: $\mathrm{U}$ and $\mathrm{Pu}$ fission also produce other Xe isotopes, but ${ }^{136} \mathrm{Xe}$ is commonly used to trace these components. 
those associated with planetary outgassing and atmosphere formation, so mantle noble gas isotopic variability is usually interpreted in terms of the extent and timing of planetary outgassing. While qualitatively reasonable, uncertainties in partition coefficients complicate the picture because it is unclear in what direction mantle melting fractionates parent/daughter ratios. Additional uncertainty arises from the potential transport of noble-gas-rich (parent-poor) fluid phases, whose existence in the mantle is suspected but not well documented (e.g. Menzies \& Hawkesworth 1987). Finally, only little is known of the behavior of noble gases during core formation (Matsuda et al 1993).

Most radiogenic noble gases are produced directly or indirectly by the decay of just three elements: K, U, and Th. These elements do not fractionate strongly from each other during most mantle processes (Jochum et al 1983), and they have comparably long half-lives. Given the geochemical similarity of the daughter elements, this fact suggests there should be strong correlations among radiogenic noble gas isotopic ratios in mantle materials.

Unlike traditional "stable isotope ratios," which typically vary over tens of per mil, noble gas isotopic ratios vary over a few percent to orders of magnitude. Some mass fractionation associated with physical processes probably occurs, but for most isotopic ratios it is insignificant.

\section{MANTLE NOBLE GASES}

\section{Samples}

There are serious restrictions on mantle-derived materials suitable for noble gas analysis. Although geothermal gases can be highly enriched in mantle-derived noble gases, with the exception of $\mathrm{He}$, the mantle component is difficult to detect in the presence of admixed atmospheric gases. Whole rock volcanic samples are not useful either because they are highly outgassed during emplacement. Basalt glass in submarine and occasionally in subglacial environments is quenched at sufficiently high pressures that magmatic outgassing of noble gases has not been complete. Fresh basalt glass is ideal for noble gas studies, but alteration, diffusion, and post-eruptive radiogenic ingrowth limit the age of suitable samples to less than a few million years. Olivine, pyroxene, and diamond crystals also carry mantle noble gases, within inclusions of fluid and melt. These phases preserve recognizable noble gas signatures for at least a few million years and, especially in the case of diamonds, possibly for much longer. However, samples older than a few million years often suffer ingrowth of radiogenic and cosmic-ray spallogenic noble gases for which correction is impossible; most samples suitable for noble gas analyses are young $(<10 \mathrm{Ma})$. In contrast to other radiogenic isotope systems (e.g. $\mathrm{Sr}, \mathrm{Nd}, \mathrm{Pb}, \mathrm{Os}$ ), noble gas studies are largely restricted to materials recently extracted from the mantle. 


\section{Helium}

Helium holds a special place in mantle geochemistry studies. Because of its low atomic weight, $\mathrm{He}$ is the only element not presently retained by the Earth's gravitational field, so its atmospheric abundance is extremely low. As a result, air contamination effects that plague $\mathrm{Ne}-\mathrm{Ar}-\mathrm{Kr}$-Xe analyses (see below) are absent for He. In addition, the isotopic variability in mantle samples is enormous. Relative to the atmospheric ${ }^{3} \mathrm{He} /{ }^{4} \mathrm{He}$ ratio of $1.39 \times 10^{-6}$ (commonly denoted as $R_{A}$ ), mantle samples range from about 3 to 30 times higher ( 3 to $30 \times R_{A}$, or simply 3 to $30 \mathrm{R}_{\mathrm{A}}$ ). (Helium isotope ratios are commonly reported as the ratio of nonradiogenic ${ }^{3} \mathrm{He}$ to radiogenic ${ }^{4} \mathrm{He}$, unlike other radiogenic isotope ratios in which the nonradiogenic isotope is the denominator.)

A great deal of data on the He isotopic composition of volcanic materials has been published over the years, providing what is probably a fairly complete representation of the variability in mantle ${ }^{3} \mathrm{He} /{ }^{4} \mathrm{He}$, at least to the extent that such variability is expressed at the Earth's surface. For interpreting the evolution of the mantle-atmosphere system, the most important volcanic settings are midocean ridges, which are believed to sample the uppermost mantle, and ocean islands, derived from mantle plumes that sample other and possibly deeper portions of the mantle. Although He isotope data are also available for convergent margins and continental volcanic provinces, these environments are potentially subject to complicating shallow-level effects and are not discussed here.

The variability in He isotope ratios in ridges and ocean islands constrains the time-integrated ${ }^{3} \mathrm{He} /(\mathrm{U}+\mathrm{Th})$ ratio of various parts of the mantle and, equally importantly, provides a framework for interpreting the heavier noble gas data. Such a framework is of value because heavier noble gas data are both much more limited and are frequently less reliable. Given our expectation that noble gas isotopic ratios should be correlated, the He isotope framework guides selection of key sampling localities for heavier noble gas work, aids in identification of atmospheric contamination effects, and plays a critical role in the interpretation of the heavier noble gas data.

The mid-ocean ridge source is by far the best-studied mantle environment because quenched basalt glasses are ubiquitous and are readily analyzed. Midocean ridge basalt (MORB) He isotope ratios range from 6 to $16 \mathrm{R}_{\mathrm{A}}$, with the distribution strongly peaked at $8 \mathrm{R}_{\mathrm{A}}$ (Figure 1). The general interpretation of this distribution is that the MORB mantle carries rather uniform ${ }^{3} \mathrm{He} /{ }^{4} \mathrm{He}$ ratios in the range 7-9 $R_{A}$, but the MORB source may be modified to apparently "anomalous" values as a result of input from other sources. Most commonly, these anomalous ratios are attributed to involvement of a component derived from a nearby hotspot. For example, the He isotope ratios along the ridges north and south of Iceland are uniformly higher than other North Atlantic MORBs. The ratios rise approaching Iceland (Poreda et al 1986), and ratios on Iceland 


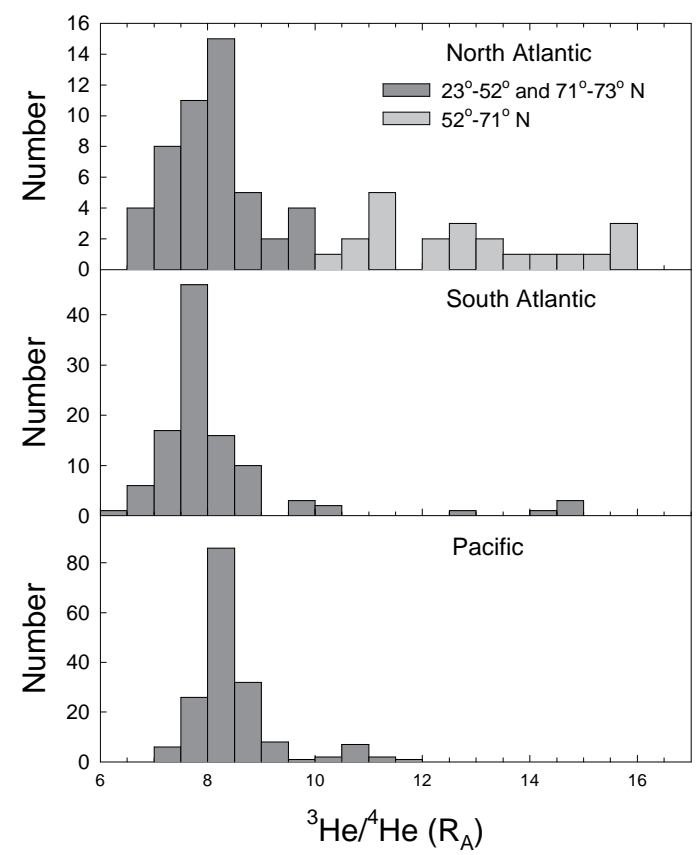

Figure $1 \mathrm{He}$ isotope ratios in mid-ocean ridge basalt (MORB) glasses. Most MORBs have ${ }^{3} \mathrm{He} /{ }^{4} \mathrm{He}$ ratios between 7 and $9 \mathrm{R}_{\mathrm{A}}$, a range taken as characteristic of the depleted upper mantle. Prominent exceptions are the higher values in the vicinity of Iceland $\left(52^{\circ}-71^{\circ} \mathrm{N}\right)$ and the Easter microplate, and these are attributed to involvement of a plume-derived component. Data compilation courtesy of D Graham from literature sources and unpublished work; see Graham et al (1992b).

itself are even higher (to $28 \mathrm{R}_{\mathrm{A}}$; Condomines et al 1983, Kurz et al 1985). As demonstrated by ${ }^{3} \mathrm{He} /{ }^{4} \mathrm{He}$ of $\sim 11 \mathrm{R}_{\mathrm{A}}$ in Easter microplate basalts, offaxis plumes can also influence MORB He (Poreda et al 1993). Similarly, interactions with nearby hotspots carrying low ${ }^{3} \mathrm{He} /{ }^{4} \mathrm{He}$ ratios (see below) can lower MORB ratios below the strong $8-\mathrm{R}_{\mathrm{A}}$ peak, at least slightly (Graham et al 1992b). Although the exact nature of the interaction between MORB and plume components is uncertain, the close spatial proximity and similarity in isotopic composition leave little doubt that many of the anomalous ${ }^{3} \mathrm{He} /{ }^{4} \mathrm{He}$ ratios represent mixing with hotspot-related material.

Several recent studies have also identified anomalous ${ }^{3} \mathrm{He} /{ }^{4} \mathrm{He}$ ratios in MORBs far from known hotspots. For example, ratios up to $11 \mathrm{R}_{\mathrm{A}}$ occur at $16^{\circ} \mathrm{S}$ on the East Pacific Rise (Mahoney et al 1994), and values as low as 6.2 $\mathrm{R}_{\mathrm{A}}$ are found at $33^{\circ} \mathrm{S}$ on the Mid-Atlantic Ridge (Hanan et al 1992). These unusual ratios coincide with other distinctive chemical and isotopic characteristics 
and have been attributed to passive entrainment of small isotopically distinct bodies (blobs) within the upper mantle MORB source. Their ultimate source may be the same reservoir responsible for ocean island volcanism (Graham et al 1996).

The sharply peaked ${ }^{3} \mathrm{He} /{ }^{4} \mathrm{He}$ distribution observed in normal MORBs in Figure 1 indicates that the upper mantle has a strikingly uniform ${ }^{3} \mathrm{He} /{ }^{4} \mathrm{He}$ ratio of about $8 \mathrm{R}_{\mathrm{A}}$. In the following discussion we refer to values between 7 and $9 \mathrm{R}_{\mathrm{A}}$ as the normal MORB range. An important implication of the sharply peaked MORB distribution is that, because the particular value of $8 \mathrm{R}_{\mathrm{A}}$ is not preferred for any obvious reason, it is likely to be unique to the MORB reservoir. Therefore a measured ${ }^{3} \mathrm{He} /{ }^{4} \mathrm{He}$ ratio of $8 \mathrm{R}_{\mathrm{A}}$ may be diagnostic of a component derived from the MORB source, or at least He that is in communication with that source.

In contrast to the uniformity observed in most MORBs, He isotope ratios in ocean island basalts (OIBs) vary from $\sim 4$ to $\sim 32 \mathrm{R}_{\mathrm{A}}$ (Figure 2 ). The highest known values occur on the two largest hotspots, Iceland and Hawaii, while the

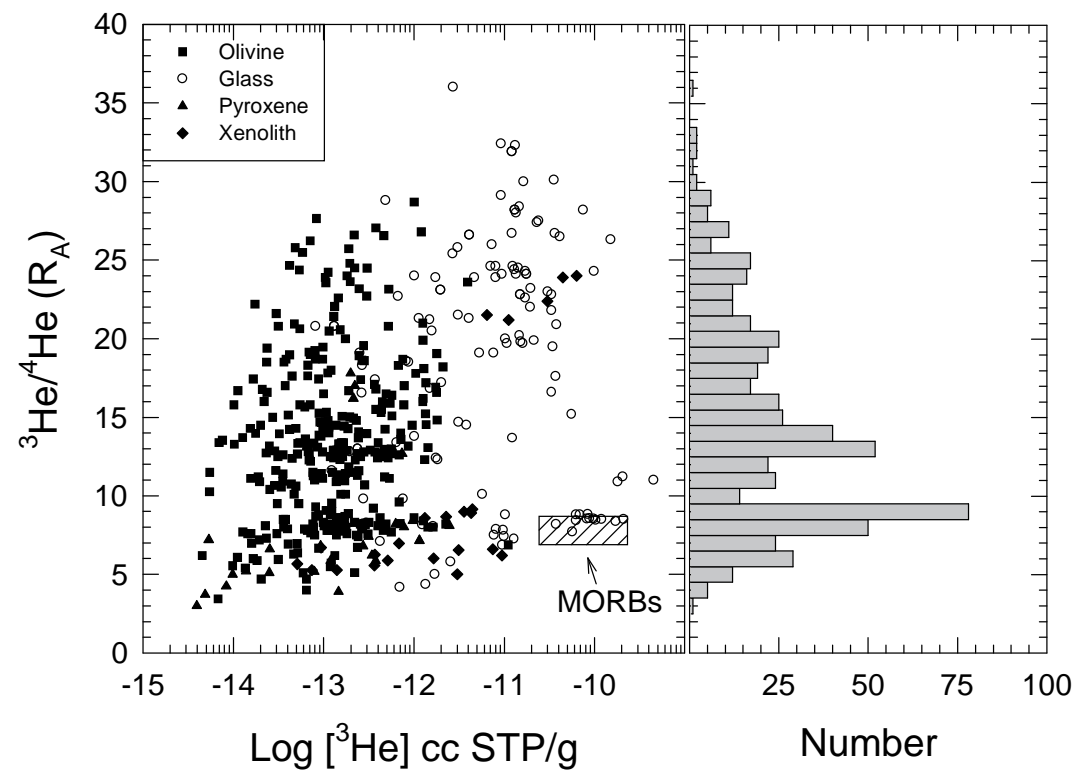

Figure $2 \mathrm{He}$ isotope ratios in ocean island basalts (OIBs) and relationship to ${ }^{3} \mathrm{He}$ concentration. OIB ${ }^{3} \mathrm{He} /{ }^{4} \mathrm{He}$ ratios extend to both higher and lower values than MORBs. The prominent histogram peak at the MORB value suggests that the depleted upper mantle plays an important role in the OIB He budget. Box indicates typical MORB range (after Sarda \& Graham 1990). Locations and data sources are listed in the caption to Figure 3. 
lowest ratios are found at several small hotspot volcanos, including St. Helena $\left(6 R_{A}\right)$, Guadalupe $\left(4 R_{A}\right)$, and the Azores $\left(4 R_{A}\right)$. Many hotspot volcanos have ${ }^{3} \mathrm{He} /{ }^{4} \mathrm{He}$ ratios intermediate to these extremes. The histogram shown in Figure 2 exhibits a peculiar double-peaked distribution, with maxima at 8 and $13 \mathrm{R}_{\mathrm{A}}$, separated by a pronounced minimum at about $10 \mathrm{R}_{\mathrm{A}}$ (Craig 1990).

As shown in Figure 3, lavas from individual ocean island volcanos span a large range in ${ }^{3} \mathrm{He} /{ }^{4} \mathrm{He}$. However, as first noted by Craig (1990), this variability is systematic. Each volcano is characterized by ratios either exclusively greater than or equal to the MORB ratio, or exclusively less than or equal to the MORB ratio. This tendency is shown in Figure 3, where only two volcanos (Heard and Kerguelen) clearly straddle the shaded MORB range. Apparently, hotspot volcanos can be characterized either as "low ${ }^{3} \mathrm{He} /{ }^{4} \mathrm{He}$ " or "high ${ }^{3} \mathrm{He} /{ }^{4} \mathrm{He}$ " (some have only MORB-like ratios and cannot be classified), potentially implying a fundamental dichotomy in mantle plume sources. If so, the near-total absence of

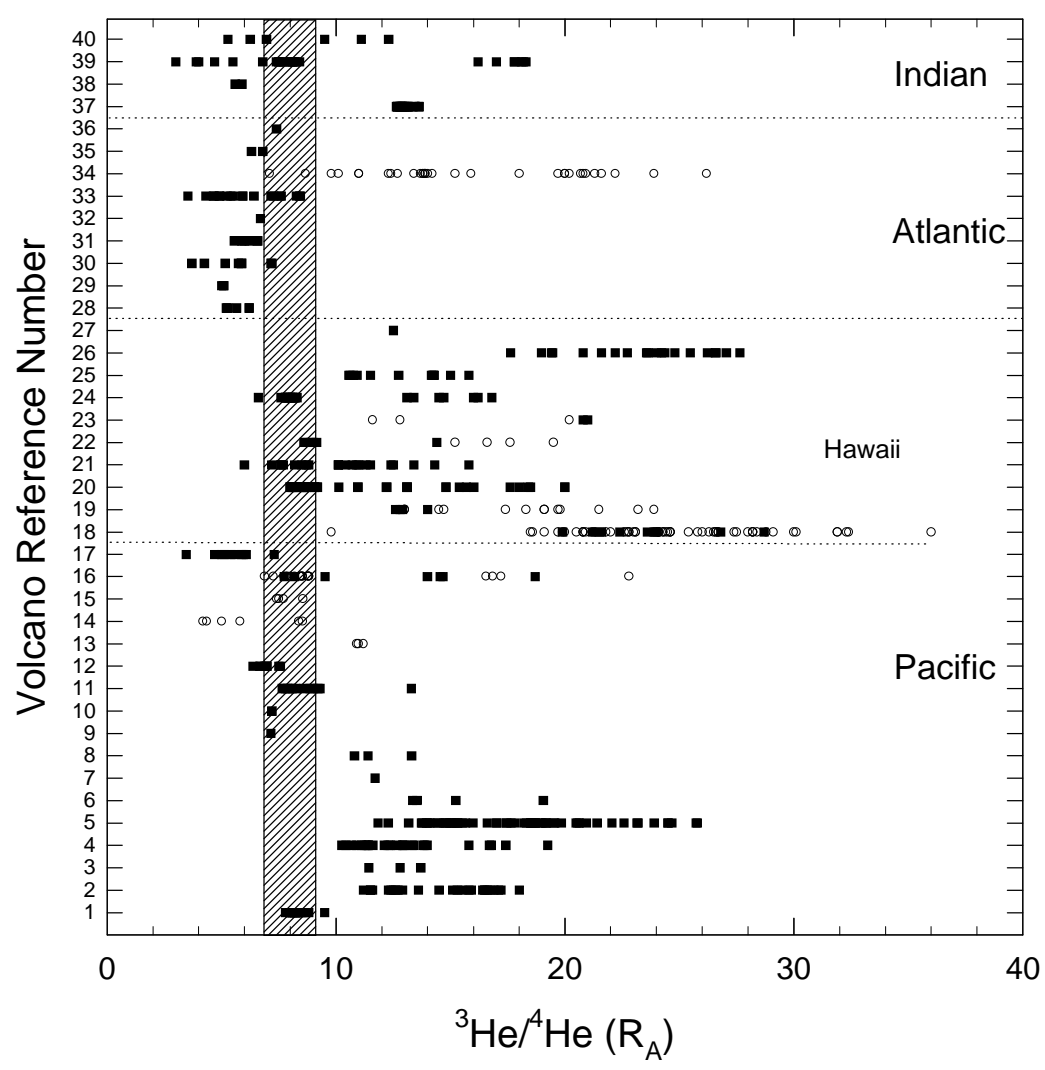


volcanos carrying both high ${ }^{3} \mathrm{He} /{ }^{4} \mathrm{He}$ and low ${ }^{3} \mathrm{He} /{ }^{4} \mathrm{He}$ lavas suggests either that these two sources do not usually mix within a single volcano or, if they do, that one component completely dominates the He isotopic signature. Alternatively, "low ${ }^{3} \mathrm{He} /{ }^{4} \mathrm{He}$ " lavas may simply be an artifact of crustal contamination (Hilton et al 1995, see below).

High ${ }^{3} \mathrm{He} /{ }^{4} \mathrm{He}$ ratios are commonly thought to be carried by mantle plumes rising from a deep portion of the mantle (possibly the lower mantle or even the core mantle boundary). This source must have a higher time-integrated ${ }^{3} \mathrm{He} /(\mathrm{U}+\mathrm{Th})$ ratio than the MORB mantle and so is commonly considered to be a less degassed reservoir. A deep mantle source is consistent with most conceptions of plume formation and potentially provides a region to isolate high ${ }^{3} \mathrm{He} /{ }^{4} \mathrm{He}$ mantle from convective mixing with the lower ${ }^{3} \mathrm{He} /{ }^{4} \mathrm{He}$ MORB source. ${ }^{3} \mathrm{He} /{ }^{4} \mathrm{He}$ variability is often taken as the strongest evidence for a layered mantle (Kaneoka et al 1983, Allegre et al 1983, 1995). A genetic relationship between a plume and high ${ }^{3} \mathrm{He} /{ }^{4} \mathrm{He}$ ratios has recently been demonstrated on Iceland, where seismic tomography suggests a hot zone upwelling from a depth of at least $400 \mathrm{~km}$ (Wolfe et al 1997). The highest ${ }^{3} \mathrm{He} /{ }^{4} \mathrm{He}$ ratios observed in the Iceland neovolcanic zone occur where the imaged plume intersects the lithosphere.

Figure 3 He isotope ratio distributions in basalts from individual ocean islands. Individual islands span a broad range in ${ }^{3} \mathrm{He} /{ }^{4} \mathrm{He}$ ratio, but with the exception of Heard and Kerguelen (\#39 and 40), no volcano has lavas with ratios clearly on both sides of the MORB value (shaded). Open symbols are basalt glasses, closed are crystals. We have not included samples analyzed by fusion because radiogenic and cosmogenic gases may be released by this technique. Volcanos are ordered arbitrarily by location and are keyed as follows: 1. Mas Afuera, 2. Mas a Tierra (Farley et al 1993), 3. Savai'i, 4. Upolu, 5. Tutuila, 6. Manu'a (Farley et al 1992; K Farley, unpublished data), 7. Macdonald Seamount, 8. Rapa (Tatsumoto et al 1990; H Craig, unpublished data cited in Eiler et al 1997), 9. Tubuai (Graham et al 1992a), 10. Rurutu (Tatsumoto et al 1990; HCraig, unpublished data cited in Eiler et al 1997), 11. Pitcairn, 12. Gambiers (K Farley \& H Craig, unpublished data), 13. Mehetia, 14. Teahitia, 15. Rocard (Staudacher \& Allegre 1989), 16. Galapagos (Graham et al 1993), 17. Guadalupe (Farley et al 1991), 18. Loihi Seamount (Rison \& Craig 1983, Kurz et al 1983, Staudacher et al 1986, Honda et al 1993, Hiyagon et al 1993), 19. Kilauea (Kurz et al 1983, Rison \& Craig 1983, Honda et al 1993), 20. Mauna Loa (Kurz et al 1983, 1987, 1996), 21. Mauna Kea (Kurz et al 1996), 22. Hualalai (Staudacher et al 1986, Kurz et al 1983), 23. Mahukona (Garcia et al 1990), 24. Haleakala (Kurz et al 1987), 25. Koolau (Roden et al 1994), 26. Kauai (Rison \& Craig 1983, Mukhopadhyay et al 1996), 27. Niihau (Rison \& Craig 1983), 28. Gough, 29. Tristan da Cunha (Kurz et al 1982), 30. St. Helena (Graham et al 1992a), 31. Canary Islands, 32. Madeira (Vance et al 1989), 33. Sao Miguel (Kurz et al 1997), 34. Iceland (Condomines et al 1983, Kurz et al 1985), 35. Jan Mayen (Kurz et al 1982), 36. Prince Edward (Kurz et al 1982), 37. Reunion (Staudacher et al 1986, 1990, Graham et al 1990), 38. Grand Comores (Kaneoka et al 1986; H Craig, unpublished data cited in Eiler et al 1997), 39. Heard (Hilton et al 1995), 40. Kerguelen (Vance et al 1989, Valbracht et al 1996). 
Studies of the He isotopic evolution of Hawaiian volcanos mostly by Kurz and coworkers provide important insights to the role of the high ${ }^{3} \mathrm{He} /{ }^{4} \mathrm{He}$ source in hotspot volcanism. Within the Hawaiian chain, by far the highest ${ }^{3} \mathrm{He} /{ }^{4} \mathrm{He}$ ratios occur at Loihi Seamount (Kurz et al 1983, Rison \& Craig 1983), the juvenilestage present-day manifestation of the Hawaiian hotspot. In contrast, the large shield volcanos have lower ${ }^{3} \mathrm{He} /{ }^{4} \mathrm{He}$ ratios, and where detailed data exist, the ${ }^{3} \mathrm{He} /{ }^{4} \mathrm{He}$ ratios are seen to decline with time to a value indistinguishable from MORBs (Kurz et al 1987, Kurz \& Kammer 1991). These observations have been attributed to a systematic transition from a high ${ }^{3} \mathrm{He} /{ }^{4} \mathrm{He}$ plume-dominated source to one dominated by the MORB mantle as volcanos grow and migrate away from the location of a fixed plume. This would explain the prevalence of MORB-like ${ }^{3} \mathrm{He} /{ }^{4} \mathrm{He}$ ratios in the OIB database (see Figure 3)—MORB helium is a mixing endmember.

Low ${ }^{3} \mathrm{He} /{ }^{4} \mathrm{He}$ samples require a lower time-integrated ${ }^{3} \mathrm{He} /(\mathrm{U}+\mathrm{Th})$ ratio than both the high ${ }^{3} \mathrm{He} /{ }^{4} \mathrm{He}$ hotspots and the MORB mantle. In contrast to the many well-studied high ${ }^{3} \mathrm{He} /{ }^{4} \mathrm{He}$ volcanos (Figure 3), little is known about the $\mathrm{He}$ isotopic evolution or even the general variability at low ${ }^{3} \mathrm{He} /{ }^{4} \mathrm{He}$ volcanos. This dearth of data raises questions regarding the interpretation of the low values. Based on observations at Heard Island, Hilton and coworkers (1995) suggested that ${ }^{3} \mathrm{He} /{ }^{4} \mathrm{He}$ ratios lower than the MORB value are derived from contamination of a MORB-like signature by radiogenic crustal gases, i.e. the low values may not originate in the mantle at all. A tendency for low He concentration samples (the ones most subject to crustal contamination) to have anomalously low ${ }^{3} \mathrm{He} /{ }^{4} \mathrm{He}$ ratios supports Hilton et al's hypothesis. A weak tendency for lower ${ }^{3} \mathrm{He} /{ }^{4} \mathrm{He}$ ratios in low ${ }^{3} \mathrm{He}$ concentration samples may also exist in the overall OIB database (Figure 2). Assessment of the role of crustal gases in the generation of low ${ }^{3} \mathrm{He} /{ }^{4} \mathrm{He}$ ratios in OIBs warrants further investigation, and the caution issued by Hilton et al (1995) - that low He concentration samples may be suspect—should be carefully considered. Nevertheless, the presence of ${ }^{3} \mathrm{He} /{ }^{4} \mathrm{He}$ ratios $<7 \mathrm{R}_{\mathrm{A}}$ in some MORB glasses (to $6.2 \mathrm{R}_{\mathrm{A}}$, Hanan et al 1992) provides strong evidence for low ${ }^{3} \mathrm{He} /{ }^{4} \mathrm{He}$ ratios in the mantle, at least as sampled at ridges, because it is difficult to envisage how crustal gases could play a role in such an environment.

A surprising feature of the OIB distribution shown in Figure 2 is the near absence of samples at $\sim 10 \mathrm{R}_{\mathrm{A}}$ (Craig 1990). If the variability in ${ }^{3} \mathrm{He} /{ }^{4} \mathrm{He}$ ratios reflects mixing between three components-a high ${ }^{3} \mathrm{He} /{ }^{4} \mathrm{He}$ source $\left(>30 \mathrm{R}_{\mathrm{A}}\right)$, the MORB source ( $~ 8 \mathrm{RA})$, and a low ${ }^{3} \mathrm{He} /{ }^{4} \mathrm{He}$ component derived either from the mantle or crust-it is not clear why a minimum occurs at an intermediate ratio. Given the large OIB He database, both in terms of number of samples and number of volcanos, this observation appears to be robust, although it is possible that this signal arises from oversampling of a few volcanos such as Reunion. We are aware of no explanation for this puzzling aspect of the distribution. 


\section{Heavier Noble Gases: The Veil of Atmospheric Contamination}

The atmosphere is a serious source of contamination of the heavier noble gases in mantle-derived samples. Replicate $\mathrm{Ne}, \mathrm{Ar}$, and Xe analyses of basalt glasses, ocean island phenocrysts, and peridotite xenoliths invariably define apparent mixing trajectories passing through the atmospheric composition, suggesting heterogeneous addition of an air-like component to an isotopically distinct (mantle) composition (e.g. Fisher 1983, Marty et al 1983). This might indicate the existence of a second mantle component with air-like isotopic ratios, but this seems unlikely because $(a)$ it is difficult to see how this component could maintain a heterogeneous distribution from grain to grain in individual samples against diffusive equilibration at mantle temperatures, $(b)$ this component must carry no He because despite variability in the heavier noble gases in the replicates, He isotope ratios are constant, and $(c)$ its presence is not correlated with presumed mantle source regions. In contrast, all of these observations are expected for late-stage addition of atmospheric gases. The origin of the atmospheric contaminant remains uncertain, but it is probably added shortly before eruption (Marty et al 1983, Jambon et al 1985, Patterson et al 1990, Farley \& Craig 1994).

Atmospheric contamination complicates characterization of the heavier noble gases in the mantle. Many samples yield nearly air-like isotopic ratios of these gases, probably from pervasive contamination. Samples with low mantle noble gas concentrations (as indicated by $\mathrm{He}$, which is almost always exclusively mantle derived) are especially prone to this effect. For this reason, only a fraction of the samples studied for ${ }^{3} \mathrm{He} /{ }^{4} \mathrm{He}$ are useful for the heavier noble gases. In general, OIB samples have lower mantle noble gas contents, and hence they are more affected by contamination than are MORB glasses.

The effect of air contamination is such that measured $\mathrm{Ne}, \mathrm{Ar}$, and Xe isotopic ratios are lower limits to the composition of the mantle. Incremental outgassing sometimes isolates a less contaminated composition (e.g. Marty et al 1983), presumably because the mantle and atmospheric components are sited differently. Similarly, the brute force approach of replicate analyses is frequently used (e.g. Poreda \& Farley 1992). In the case of neon, isotopic deconvolution (see below) can be used to quantify the extent of air addition and to correct for it (Honda et al 1991, Farley \& Poreda 1993). For the other noble gases, correction is difficult or impossible.

\section{Neon}

Perhaps the most important recent development in the noble gas field is confirmation of non-atmospheric neon in mantle-derived rocks. Although earlier work suggested the possibility (Craig \& Lupton 1976, Poreda \& Radicati di Brozolo 1984), high precision analyses of diamonds (Honda et al 1987, Ozima 
\& Zashu 1988) and MORB glasses (Sarda et al 1988) revealed that the mantle is elevated in ${ }^{20} \mathrm{Ne} /{ }^{22} \mathrm{Ne}$ and ${ }^{21} \mathrm{Ne} / 22 \mathrm{Ne}$ relative to the atmosphere. In a plot of ${ }^{20} \mathrm{Ne} /{ }^{22} \mathrm{Ne}$ vs ${ }^{21} \mathrm{Ne} /{ }^{22} \mathrm{Ne}$, MORBs lie on a fairly well-defined array, anchored by the atmospheric point, and extend to values as high as $\sim 13$ for ${ }^{20} \mathrm{Ne} /{ }^{22} \mathrm{Ne}$ (vs 9.8 in air) and $\sim 0.07$ for ${ }^{21} \mathrm{Ne} /{ }^{22} \mathrm{Ne}$ (vs 0.029) (Figure 4). The "MORB array" is most readily interpreted as the result of air contamination of a MORB composition lying at or beyond the high end of the array. By analogy to the uniformity of ${ }^{3} \mathrm{He} /{ }^{4} \mathrm{He}$ ratios in MORBs, it is generally assumed that the MORB source can be described by a single Ne isotopic composition. However, given the fairly large uncertainties in neon measurements and the presence of atmospheric contamination, this conclusion cannot be proven. The scatter in the MORB Ne data relative to the air-mixing line hints at source heterogeneity, but further high precision analyses are required for a critical assessment.

$\mathrm{Ne}$ isotopic enrichments have also been found in high ${ }^{3} \mathrm{He} /{ }^{4} \mathrm{He}$ materials, most significantly in Loihi Seamount glasses (Honda et al 1991, Hiyagon et al 1992, Valbracht et al 1997) and in xenoliths from Samoa (Poreda \& Farley 1992). These samples do not plot on the MORB array in Figure 4 but on distinct and steeper trajectories. The individual isotopic arrays each have a characteristic slope rising from the atmospheric point to a ${ }^{20} \mathrm{Ne} /{ }^{22} \mathrm{Ne}$ ratio of $\sim 12.5$. Again these arrays are most easily attributed to air contamination, but the mantle sources sampled in these settings must have isotopically distinct $\mathrm{Ne}$. As shown in Figure 4, the slope of these arrays is positively correlated with the associated ${ }^{3} \mathrm{He} /{ }^{4} \mathrm{He}$ ratios.

The enrichment in ${ }^{21} \mathrm{Ne}$ is reasonably attributed to nucleogenic production in the mantle from the reactions ${ }^{18} \mathrm{O}(\alpha, \mathrm{n}){ }^{21} \mathrm{Ne}$ and ${ }^{24} \mathrm{Mg}(\mathrm{n}, \alpha){ }^{21} \mathrm{Ne}$ (Wetherill 1954). The ${ }^{20} \mathrm{Ne} / 22 \mathrm{Ne}$ enrichments are more difficult to explain because no known nuclear reaction can substantially modify this ratio in the atmosphere or in the mantle. The distinction between MORB and Loihi Ne led Honda et al (1991) to suggest that $\mathrm{Ne}$ in mantle samples represents a mixture of three sources: "solar" Ne captured by the Earth during accretion and characterized by ${ }^{20} \mathrm{Ne} /{ }^{22} \mathrm{Ne}$ and ${ }^{21} \mathrm{Ne} /{ }^{22} \mathrm{Ne}$ ratios of 13.6 and 0.032 , respectively; nucleogenic $\mathrm{Ne}$ (nearly pure ${ }^{21} \mathrm{Ne}$ ); and atmospheric contamination. In this view, the Earth accreted with solar-like $\mathrm{Ne}$, and radioactive decay simply moves the mantle composition to the right (higher ${ }^{21} \mathrm{Ne} /{ }^{22} \mathrm{Ne}$ ) as a function of time and degree of outgassing [i.e. time-integrated ${ }^{22} \mathrm{Ne} /(\mathrm{U}+\mathrm{Th})$ ].

If this suggestion is correct, the known compositions of the endmembers permit deconvolution to reveal the fraction of each component present in a mantle sample. A critical result of this deconvolution is identification of ${ }^{21} \mathrm{Ne} /{ }^{22} \mathrm{Ne}$ ratios of mantle sources free of the atmospheric overprint. The ability to correct for atmospheric contamination arises from the fact that the ${ }^{20} \mathrm{Ne} /{ }^{22} \mathrm{Ne}$ ratio of the mantle is distinct from that of the atmosphere, and this distinction cannot 


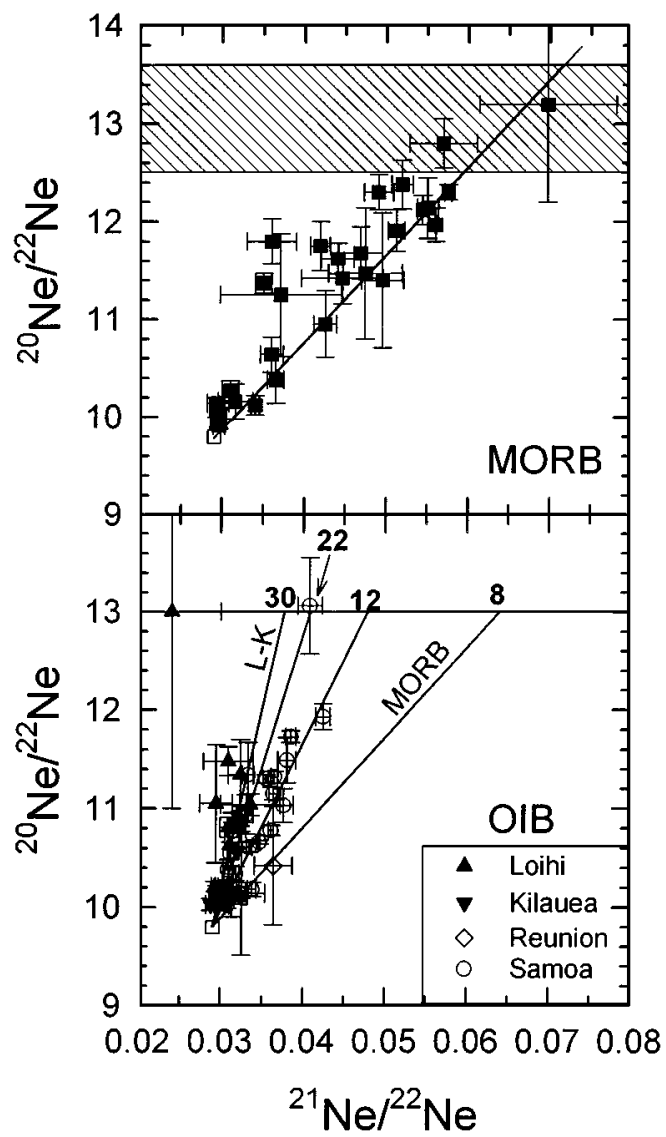

Figure $4 \mathrm{Ne}$ isotope ratios in MORB and OIB samples. Analyses from a given setting define air-mixing trajectories with mantle components having ${ }^{20} \mathrm{Ne} / 22 \mathrm{Ne}$ up to $\sim 13$. Both panels show the MORB correlation line of Sarda et al (1988); the lower panel also shows the correlation lines for Loihi-Kilauea (L-K, Honda et al 1991) and two suites of Samoan xenoliths (Poreda \& Farley 1992). The slope on this diagram is correlated with ${ }^{3} \mathrm{He} /{ }^{4} \mathrm{He}$ (shown on figure at ${ }^{20} \mathrm{Ne} /{ }^{22} \mathrm{Ne}=13$, in $\mathrm{R}_{\mathrm{A}}$ units). The open square is the atmospheric composition. The shaded band indicates various estimates of the ${ }^{20} \mathrm{Ne} /{ }^{22} \mathrm{Ne}$ ratio with which the Earth accreted (Honda et al 1991, 1993, Farley \& Poreda 1993). Data are from Sarda et al 1988, Marty 1989, Hiyagon et al 1992, Honda et al 1991, Poreda \& Farley 1992. Samples with air-like compositions have been excluded. Figure modified after Porcelli \& Wasserburg (1995a). 
be attributed to radioactive decay in either reservoir. If the entire mantle has a constant and known ${ }^{20} \mathrm{Ne} / 22 \mathrm{Ne}$ ratio [Honda et al (1991) assume a solar value of 13.6], then any lower ratio measured in mantle samples must be due to addition of air with a ratio of 9.8. In effect, the uncontaminated mantle ${ }^{21} \mathrm{Ne} /{ }^{22} \mathrm{Ne}$ ratio for any given sample can be derived by extending a line from the atmospheric point through the measured composition in Figure 4. The mantle ${ }^{21} \mathrm{Ne} /{ }^{22} \mathrm{Ne}$ ratio is found where the extension of this line intersects the mantle ${ }^{20} \mathrm{Ne} /{ }^{22} \mathrm{Ne}$ ratio. Whether the solar ratio is the correct ${ }^{20} \mathrm{Ne} /{ }^{22} \mathrm{Ne}$ ratio to use for the mantle is unclear (Farley \& Poreda 1993); a range of ratios are observed in meteorites (including the solar value), but it is unknown which, if any, of these values are appropriate for the material from which the Earth accreted. However, it makes little difference which value we choose for the deconvolution, as the calculated ${ }^{21} \mathrm{Ne} /{ }^{22} \mathrm{Ne}$ ratios of the mantle will shift in absolute terms only slightly and will not change at all in relative terms.

The correlation between the slope in ${ }^{20} \mathrm{Ne} /{ }^{22} \mathrm{Ne}$ vs ${ }^{21} \mathrm{Ne} / 22 \mathrm{Ne}$ space and the ${ }^{3} \mathrm{He} /{ }^{4} \mathrm{He}$ ratio is readily understood in the context of the Honda et al (1991) model. The variation in ${ }^{21} \mathrm{Ne} /{ }^{22} \mathrm{Ne}$ must reflect the time-integrated ratio of $(\mathrm{U}+\mathrm{Th}) /{ }^{22} \mathrm{Ne}$, and the ${ }^{4} \mathrm{He} /{ }^{3} \mathrm{He}$ ratio must reflect the time integrated $(\mathrm{U}+\mathrm{Th}) /{ }^{3} \mathrm{He}$ ratio. The ratio of ${ }^{4} \mathrm{He} /{ }^{21} \mathrm{Ne}$ produced by radioactive decay in the mantle will be nearly constant, with a best estimate of $0.5-1 \times 10^{7}$ (Kyser \& Rison 1982, Hunemohr 1992, Yatsevich \& Honda 1997). Given coherent behavior of $\mathrm{He}$ and $\mathrm{Ne}$ during mantle processing, the parent/daughter ratios will scale together, which will lead to a correlation between $\mathrm{He}$ and $\mathrm{Ne}$ isotopic ratios.

Patterson et al (1994) have demonstrated that the correlation between He and $\mathrm{Ne}$ isotopic ratios is very strong. Given the known production ratio ${ }^{4} \mathrm{He} /{ }^{21} \mathrm{Ne}$, it is possible to directly calculate the ${ }^{3} \mathrm{He} /{ }^{4} \mathrm{He}$ ratio expected in a sample simply from the air-corrected ${ }^{21} \mathrm{Ne} /{ }^{22} \mathrm{Ne}$ ratio. These authors assume that the Earth accreted with a primordial solar-like ${ }^{3} \mathrm{He} /{ }^{4} \mathrm{He}$ ratio of $\sim 285 \mathrm{R}_{\mathrm{A}}$ and, further, that the relative impact of radioactive decay on $\mathrm{He}$ and $\mathrm{Ne}$ isotopic systematics can be estimated by assuming the solar ratio of these gases (i.e. ${ }^{3} \mathrm{He} /{ }^{22} \mathrm{Ne}$ ) within the Earth. The only additional required assumption is that $\mathrm{He}$ and $\mathrm{Ne}$ have not fractionated significantly from each other over geologic time. (Note that late-stage fractionation, e.g. associated with eruption, is not a problem for this calculation because it occurs too recently to affect isotopic systematics.) In a compilation of data from a range of tectonic settings (mid-ocean ridges, ocean islands, back-arcs, kimberlites), the ${ }^{3} \mathrm{He} /{ }^{4} \mathrm{He}$ ratio calculated from the observed $\mathrm{Ne}$ isotopic ratio is typically within a few $\mathrm{R}_{\mathrm{A}}$ units of the observed ${ }^{3} \mathrm{He} /{ }^{4} \mathrm{He}$ ratio. This remarkable correlation provides strong evidence that mantle processes do not effectively separate $\mathrm{He}$ and $\mathrm{Ne}$ from each other and suggests a near-solar mantle $\mathrm{He} / \mathrm{Ne}$ ratio [whether the value is exactly solar-like, however, is still debated (Honda \& McDougall 1997)]. 
A crucial implication of non-atmospheric mantle ${ }^{20} \mathrm{Ne} /{ }^{22} \mathrm{Ne}$ is that the atmosphere cannot have been a closed-system repository for mantle-derived gases throughout Earth history. If the atmosphere and mantle are genetically related and closed to external Ne exchange, then they should share the same ${ }^{20} \mathrm{Ne} /{ }^{22} \mathrm{Ne}$ ratio. The fact that they do not means either they are not genetically related or the atmosphere has been modified by additional processes. Many arguments have been offered in support of a late bombardment of the Earth with volatilerich (cometary?) material. If the early Earth accreted from material with solar $\mathrm{Ne}$, but this postulated late-stage material had a ${ }^{20} \mathrm{Ne} /{ }^{22} \mathrm{Ne}$ ratio $<9.8$ that now dominates the atmospheric Ne inventory, then the paradox is solved. Alternatively, it is possible that the atmosphere has experienced mass-fractionating $\mathrm{Ne}$ loss. Models show that hydrodynamic escape from a planetary body can fractionate isotopic ratios of residual atmospheric gases (Hunten et al 1987, Zahnle et al 1990). In the case of the early Earth, hydrodynamic escape of $\mathrm{H}_{2}$ is possible and might have removed ${ }^{20} \mathrm{Ne}$ in preference to ${ }^{22} \mathrm{Ne}$, which would effect the necessary reduction from the solar to the atmospheric ${ }^{20} \mathrm{Ne} /{ }^{22} \mathrm{Ne}$ ratio (Sarda et al 1988, Marty 1989). The amount of Ne removal required to accomplish this reduction is very model dependent but must be large. Unlike the ${ }^{20} \mathrm{Ne} /{ }^{22} \mathrm{Ne}$ ratio, there is no clear isotopic distinction between mantle and atmosphere in ${ }^{38} \mathrm{Ar} /{ }^{36} \mathrm{Ar}$ (another ratio unaffected by decay), which suggests that Ar was unaffected by the putative hydrodynamic escape. Unfortunately it is not possible to use this as a test for the occurrence of $\mathrm{Ne}$ fractionation because the expected degree of fractionation of the two elements is again model dependent; under some conditions $\mathrm{Ne}$ can be severely fractionated without affecting Ar (Zahnle et al 1990).

\section{Argon}

Next to He, the largest published data base for the noble gases is for Ar. In MORBs, measured ${ }^{40} \mathrm{Ar} /{ }^{36} \mathrm{Ar}$ ratios range from slightly above the atmospheric value (295.5) to as high as 40,000 (Figure 5; Sarda et al 1985, Burnard et al 1997). These results require that the MORB mantle be characterized by extremely radiogenic ${ }^{40} \mathrm{Ar} /{ }^{36} \mathrm{Ar}$ ratios, with the value of 40,000 providing a reasonable lower limit in the presence of potential air contamination. The ${ }^{40} \mathrm{Ar} /{ }^{36} \mathrm{Ar}$ ratio of the high ${ }^{3} \mathrm{He} /{ }^{4} \mathrm{He}$ source is more poorly known. The earliest analyses of Loihi Seamount glasses indicated nearly air-like ratios (Allegre et al 1983), but more recent measurements in which great care was taken to minimize potential contamination revealed higher ratios, up to about 5,000 (Hiyagon et al 1992, Valbracht et al 1997).

The relationship between $\mathrm{He}$ and Ar isotopes is shown in Figure 5. What is apparent from this figure is that a large range of ${ }^{40} \mathrm{Ar} /{ }^{36} \mathrm{Ar}$ ratios can exist at any given ${ }^{3} \mathrm{He} /{ }^{4} \mathrm{He}$ ratio, but there is an apparent tendency for lower maximum 


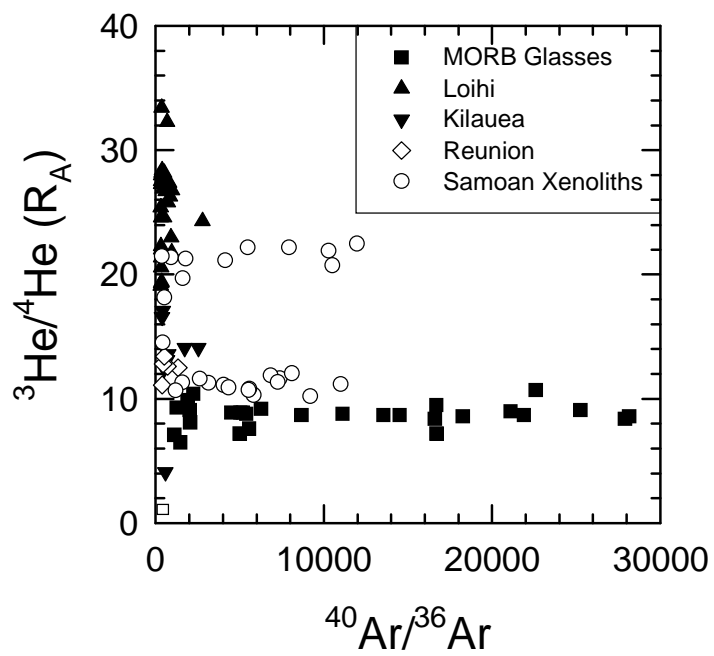

Figure 5 He-Ar systematics of MORB and OIB samples. At any given ${ }^{3} \mathrm{He} /{ }^{4} \mathrm{He}$ ratio, a wide range of ${ }^{40} \mathrm{Ar} /{ }^{36} \mathrm{Ar}$ is found, consistent with atmospheric addition. The MORB mantle is thought to have a ${ }^{40} \mathrm{Ar} /{ }^{36} \mathrm{Ar}$ ratio $>40,000$ (Burnard et al 1997). There is a general tendency toward lower maximum ${ }^{40} \mathrm{Ar} /{ }^{36} \mathrm{Ar}$ at higher ${ }^{3} \mathrm{He} /{ }^{4} \mathrm{He}$. Although controversial, these data along with other arguments suggest the high ${ }^{3} \mathrm{He} /{ }^{4} \mathrm{He}$ mantle has a ${ }^{40} \mathrm{Ar} /{ }^{36} \mathrm{Ar}$ ratio of about 5,000. The open square is the atmospheric composition. Figure modified after Porcelli \& Wasserburg (1995a). Data sources are as listed by Porcelli \& Wasserburg (1995a).

${ }^{40} \mathrm{Ar} /{ }^{36} \mathrm{Ar}$ at higher ${ }^{3} \mathrm{He} /{ }^{4} \mathrm{He}$. The range at any given value is consistent with air contamination, which affects only Ar. The lower maximum ${ }^{40} \mathrm{Ar} /{ }^{36} \mathrm{Ar}$ values at higher ${ }^{3} \mathrm{He} /{ }^{4} \mathrm{He}$ can be attributed either to a tendency for higher degrees of contamination in high ${ }^{3} \mathrm{He} /{ }^{4} \mathrm{He}$ samples or to a real correlation in mantle composition, from low ${ }^{3} \mathrm{He} /{ }^{4} \mathrm{He}$ and high ${ }^{40} \mathrm{Ar} /{ }^{36} \mathrm{Ar}$ ratios in MORBs to high ${ }^{3} \mathrm{He} /{ }^{4} \mathrm{He}$ and intermediate ${ }^{40} \mathrm{Ar} /{ }^{36} \mathrm{Ar}$ in some OIBs. Although there are reasons to believe that contamination may be more serious in OIB samples such as those from Loihi Seamount, the general consensus now is that the high ${ }^{3} \mathrm{He} /{ }^{4} \mathrm{He}$ mantle has a ${ }^{40} \mathrm{Ar} /{ }^{36} \mathrm{Ar}$ ratio of about $3000-6000$ (Farley \& Poreda 1993, Burnard et al 1994, Ozima 1994).

Although not commonly measured to high precision, no convincing variations in mantle ${ }^{38} \mathrm{Ar} /{ }^{36} \mathrm{Ar}$ have been reported (Ozima 1994). Unlike ${ }^{20} \mathrm{Ne} /{ }^{22} \mathrm{Ne}$, this isotope ratio provides no mechanism for correcting for air contamination. In principle, if the Ne/Ar ratios of the contaminant and mantle are known, then the correction calculated from $\mathrm{Ne}$ can be used to estimate a correction for the other noble gases as well (Farley \& Poreda 1993). In some cases this correction clearly does not work, but in others it may (Moreira et al 1995, 1997). 


\section{Xenon}

$\mathrm{Xe}$ is a particularly challenging element for mantle noble gas geochemists. There are nine isotopes, several of which are produced by radioactive decay. Isotopic variability from the decay of the extinct nuclides ${ }^{129} \mathrm{I}$ and ${ }^{244} \mathrm{Pu}$ potentially constrain the very early degassing history of the Earth, while spontaneous fission of ${ }^{238} \mathrm{U}$ produces several Xe isotopes over the duration of Earth history. The challenge lies in determining the abundances of so many isotopes of the rarest stable noble gas with sufficiently high precision to quantify these nuclear effects.

The most common result of Xe analyses of mantle samples is detection of air-like isotopic ratios. However, some MORB glasses have unambiguously elevated ${ }^{129} \mathrm{Xe} /{ }^{130} \mathrm{Xe}$ and ${ }^{136} \mathrm{Xe} /{ }^{130} \mathrm{Xe}$ ratios compared with those of the atmosphere (Figure 6). The observed anomalies are up to about $25 \%$ for each ratio, but most are $<10 \%$. There is a strong correlation between ${ }^{129} \mathrm{Xe} /{ }^{130} \mathrm{Xe}$ and ${ }^{136} \mathrm{Xe} /{ }^{130} \mathrm{Xe}$, with the data trending upward from the atmospheric point toward the presumed MORB composition. Within measurement error, the analyses indicate that the MORB mantle has a constant enrichment in ${ }^{129} \mathrm{Xe} /{ }^{130} \mathrm{Xe}$ relative to ${ }^{136} \mathrm{Xe} /{ }^{130} \mathrm{Xe}$.

All analyzed samples from Loihi Seamount have air-like Xe isotopic compositions, even those with non air-like $\mathrm{Ne}$ and $\mathrm{Ar}$ (Hiyagon et al 1992, Honda et al

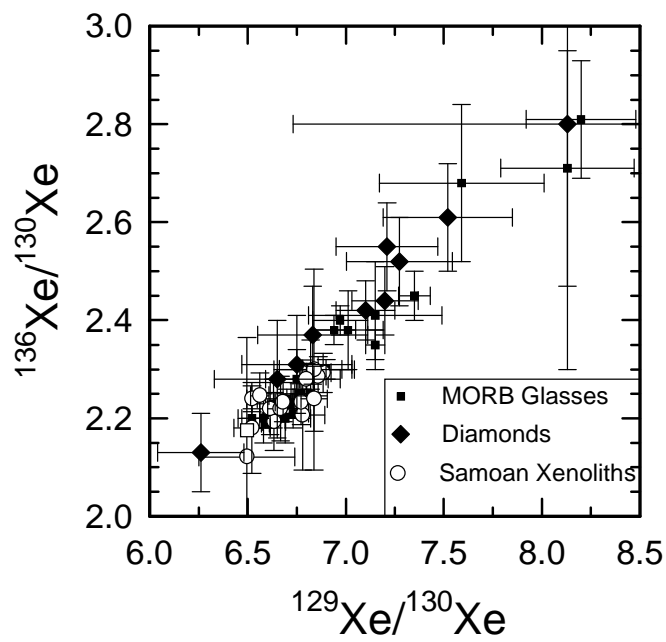

Figure 6 Xe isotope systematics of MORB glasses, Samoan xenoliths, and diamonds. All mantle samples with non-atmospheric Xe have the same slope on this plot. The open square is the atmospheric composition. (Data are from Staudacher \& Allegre 1982, Allegre et al 1983, Staudacher et al 1989, Marty 1989, Hiyagon et al 1992, Poreda \& Farley 1992, Ozima \& Zashu 1991.) 
1993, Valbracht et al 1997). The Loihi observations can be interpreted to mean either that the Xe signature of the high ${ }^{3} \mathrm{He} /{ }^{4} \mathrm{He}$ mantle is air-like or that the relative abundances of the noble gases in the contaminant and the mantle are such that Ne may be minimally contaminated while Xe is dominated by air contamination. Preferential air contamination of Xe may occur, for example, as a consequence of adsorption of atmospheric $\mathrm{Xe}$ on materials exposed to magmas.

The only high ${ }^{3} \mathrm{He} /{ }^{4} \mathrm{He}$ samples reported to have non air-like Xe compositions are Samoan xenoliths (Poreda \& Farley 1992). In two suites of xenoliths, one with ${ }^{3} \mathrm{He} /{ }^{4} \mathrm{He}=11 \mathrm{R}_{\mathrm{A}}$ and the other with ${ }^{3} \mathrm{He} /{ }^{4} \mathrm{He}=22 \mathrm{R}_{\mathrm{A}}$, the ${ }^{129} \mathrm{Xe} /{ }^{130} \mathrm{Xe}$ and ${ }^{136} \mathrm{Xe} /{ }^{130} \mathrm{Xe}$ ratios are elevated relative to the atmospheric value by up to $\sim 6 \%$ each. The precision on these analyses is comparatively poor, but the relative enrichments in ${ }^{129} \mathrm{Xe}$ and ${ }^{136} \mathrm{Xe}$ in these suites are indistinguishable from that found in MORBs (Figure 6). Unfortunately these data cannot be used to uniquely characterize the high ${ }^{3} \mathrm{He} /{ }^{4} \mathrm{He}$ mantle, even though one of the suites has a ${ }^{3} \mathrm{He} /{ }^{4} \mathrm{He}$ ratio only slightly lower than Loihi Seamount. Uncertainty in the interpretation of these data arises from the colinearity of the Samoan and MORB data in Figure 6. The He and Xe data (as well as Ne and Ar) from the Samoan xenoliths can be explained by mixing between MORB-like noble gases and a high ${ }^{3} \mathrm{He} /{ }^{4} \mathrm{He}$ source with air-like Xe. However, they can be equally well interpreted as mixing between MORB-like noble gases and a high ${ }^{3} \mathrm{He} /{ }^{4} \mathrm{He}$ source with a Xe composition plotting anywhere on (or near) the MORB Xe array. Stated differently, the Samoan xenolith data suggest only that the high ${ }^{3} \mathrm{He} /{ }^{4} \mathrm{He}$ source lies close to the MORB-air array in ${ }^{129} \mathrm{Xe} /{ }^{130} \mathrm{Xe}-{ }^{136} \mathrm{Xe} /{ }^{130} \mathrm{Xe}$ space, but the data cannot pinpoint where on the array the endmember lies.

The origin of the ${ }^{129} \mathrm{Xe}$ anomalies is the decay of ${ }^{129} \mathrm{I}$, but that of the ${ }^{136} \mathrm{Xe}$ anomaly is controversial. Are the ${ }^{136} \mathrm{Xe}$ anomalies the product of decay of extinct ${ }^{244} \mathrm{Pu}$ occurring in the first few hundred million years of Earth history, the product of ${ }^{238} \mathrm{U}$ fission over the age of the Earth, or some combination of both? Although both parents fission to the same Xe isotopes, their yield spectra are slightly different. Attempts to discriminate between the two parents using Xe in mantle samples has yielded varying results because of large analytical uncertainties (Staudacher \& Allegre 1982, Allegre et al 1986). Several unusual $\mathrm{CO}_{2}$ well gases, thought to derive in large part from the MORB mantle (Staudacher 1987), have very well-determined Xe isotope ratios similar to those of MORB glasses. Phinney et al (1978) suggested that the heavy Xe isotopes in these gases were derived at least $80 \%$ from ${ }^{238} \mathrm{U}$ fission. However, the relationship of this gas to the MORB mantle has been questioned (Ozima et al 1985, 1993). Furthermore, this deconvolution is sensitive to the baseline Xe composition assumed. The isotopic composition of terrestrial Xe is unique in the Solar System, so it is difficult to estimate the composition with which the Earth accreted 
simply from analyses of meteorites. The atmospheric composition is an inappropriate baseline because it may have experienced isotopic fraction and it must carry Xe derived from radioactive decay and outgassing occurring over the age of the Earth. Thus even if we had high precision Xe analyses of mantle samples, it is unclear that this issue could be resolved simply from the yield spectra.

As an alternative approach, Ozima \& Zashu (1991) have analyzed the Xe isotopic composition of mantle-derived diamonds. Although the origin of gases in diamonds is unknown and probably complex, $\mathrm{Xe}$ in diamonds is strikingly similar to that carried by other mantle samples (Figure 6). In addition to their relatively high precision, the importance of the diamond data is that they represent snapshots of the mantle isotopic composition through time. Ozima \& Zashu (1991) estimated that their diamonds are likely to be older than $1 \mathrm{Ga}$. If the heavy Xe anomalies were a consequence of decay of extinct ${ }^{244} \mathrm{Pu}$, then the similarity between MORBs and diamonds is reasonable: The isotopic signature was produced shortly after terrestrial accretion. In contrast, if the heavy $\mathrm{Xe}$ anomalies are from the decay of long-lived ${ }^{238} \mathrm{U}$, then one would intuitively expect MORBs to have higher anomalies because they have continued to evolve after the diamonds locked in their Xe composition. Thus, these data suggest the major source of ${ }^{136} \mathrm{Xe}$ is ${ }^{244} \mathrm{Pu}$, which is also in agreement with constraints on the $\mathrm{Pu} / \mathrm{U}$ ratio of the solar nebula (Hudson et al 1988). Nevertheless the origin of the Xe anomalies is still the subject of debate.

\section{INTERPRETATIONS AND MODELS}

The noble gas isotopic variability of mantle-derived samples requires the existence of three endmember compositions associated with MORBs and high ${ }^{3} \mathrm{He} /{ }^{4} \mathrm{He}$ and low ${ }^{3} \mathrm{He} /{ }^{4} \mathrm{He}$ lavas. Whether the mantle actually is composed of a few distinct sources that mix to form the spectrum of compositions observed in oceanic rocks, or if instead these endmembers reflect the extremes in degree of mantle processing, cannot be determined from geochemical data alone. Noble gas isotopic ratios constrain the time-integrated ratio of the noble gases to their parent nuclides, which can vary for a variety of reasons, including degassing, transfer of volatile phases within the mantle, or addition of volatiles to the mantle from external sources. An alternative class of explanations, not yet well developed, is that the parent abundances are variable and that variations in the daughter element concentrations are less significant (e.g. Graham et al 1996).

From its initial discovery, nearly all workers have accepted that mantlederived ${ }^{3} \mathrm{He}$ is primordial, i.e. a vestige of that which was originally accreted. Its strong tendency to partition from mantle solids into melts and from there into magmatic gases leads to the expectation that mantle outgassing is likely the 
dominant player in controlling its distribution. Unlike most other elements, $\mathrm{He}$ is unlikely to be returned to the mantle once it is injected into the atmosphere, primarily because it is rapidly lost from the atmosphere to space. Thus ${ }^{3} \mathrm{He}$ in mantle samples is generally thought to be both primordial and juvenile (i.e. arriving at the Earth's surface for the first time).

As an alternative to a primordial source for mantle ${ }^{3} \mathrm{He}$, Anderson (1993) suggested that all mantle ${ }^{3} \mathrm{He}$ might be attributed to relatively recent subduction of ${ }^{3} \mathrm{He}$-rich interplanetary dust particles within seafloor sediments (Merrihue 1964). Several lines of reasoning have been offered to refute this idea. Most obviously, the flux of ${ }^{3} \mathrm{He}$ out of the mantle at oceanic ridges far exceeds the current flux of ${ }^{3} \mathrm{He}$ from space (Allegre et al 1993). Although a higher extraterrestrial ${ }^{3} \mathrm{He}$ flux in the remote past cannot be ruled out, there is no reason to believe this is so (Trull 1994). Second, diffusion measurements suggest that $\mathrm{He}$ is lost from interplanetary dust at sufficiently low temperatures that it is probably completely removed within subduction zones (Hiyagon 1994). Finally, mantle $\mathrm{He} / \mathrm{Ne}$ systematics are inconsistent with subducted extraterrestrial matter (Allegre et al 1993). These observations essentially preclude a subducted interplanetary dust source for mantle ${ }^{3} \mathrm{He}$.

As indicated by its high ${ }^{21} \mathrm{Ne} /{ }^{22} \mathrm{Ne}$ and ${ }^{40} \mathrm{Ar} /{ }^{36} \mathrm{Ar}$ ratios, the MORB mantle is poor in primordial volatiles. This is usually attributed to extremely efficient extraction of volatiles from the MORB reservoir and a major (and still ongoing) role for this reservoir in the atmospheric formation process. If atmospheric Xe is predominantly derived from outgassing of the mantle, then the distinction between MORB and atmosphere in ${ }^{129} \mathrm{Xe} /{ }^{130} \mathrm{Xe}$ requires that these reservoirs separated and became isolated from each other before disappearance of ${ }^{129} \mathrm{I}$, i.e. within $\sim 100 \mathrm{Ma}$ after cessation of nucleosynthesis. This would require a very early pulse of atmosphere formation, followed by long-term isolation of the MORB and atmospheric reservoirs (Staudacher \& Allegre 1982, 1988).

The origin of the high ${ }^{3} \mathrm{He} /{ }^{4} \mathrm{He}$ component is more complex. The most common interpretation is that this reservoir has been largely isolated from outgassing and atmosphere formation, presumably by its location within the deep mantle. The heavy noble gas data are also consistent with this interpretation. Based on early results that showed nearly air-like Ar in Loihi Seamount lavas, Allegre and coworkers $(1983,1986)$ suggested that this reservoir was essentially undegassed. More recent data (Valbracht et al 1997) require some degassing, but both $\mathrm{He}$ and $\mathrm{Ne}$ (for which good endmember compositions are available) indicate that it must be substantially less degassed than the MORB source.

Much attention has focused on relating the high ${ }^{3} \mathrm{He} /{ }^{4} \mathrm{He}$ source to the mantle endmembers, identified on the basis of the isotopic ratios of $\mathrm{Sr}, \mathrm{Nd}$, and $\mathrm{Pb}$ in oceanic lavas, in an effort to understand the source's origin. Although some authors have argued for decoupling of noble gas and lithophile isotope 
signatures within oceanic lavas, presumably by metasomatism (Valbracht et al 1995), others have documented strong correlations between $\mathrm{He}$ on the one hand and $\mathrm{Sr}-\mathrm{Nd}-\mathrm{Pb}$ isotopes on the other (Kurz \& Kammer 1991, Farley et al 1992, Graham et al 1996, Eiler et al 1997). There is now a general consensus that none of the "mantle endmembers" in oceanic basalts (Zindler \& Hart 1986) is uniquely associated with high ${ }^{3} \mathrm{He} /{ }^{4} \mathrm{He}$ ratios. This observation has two explanations: He isotopes vary independently of the lithophile radiogenic isotope tracers, or the high ${ }^{3} \mathrm{He} /{ }^{4} \mathrm{He}$ mantle composition is internal to the recognized $\mathrm{Sr}-\mathrm{Nd}-\mathrm{Pb}$ endmembers. Independent variability in ${ }^{3} \mathrm{He} /{ }^{4} \mathrm{He}$ could arise as a consequence of intra-mantle metasomatism that fractionates the ${ }^{3} \mathrm{He} /(\mathrm{U}+\mathrm{Th})$ ratio without substantially affecting the lithophile parent-daughter ratios, or by fluidphase separation of noble gases from their associated lithophile elements during magmatism. Alternatively, He in the Earth's core may have high ${ }^{3} \mathrm{He} /{ }^{4} \mathrm{He}$ ratios and may leak into whatever silicate materials lie in the lowermost mantle as the core crystallizes and expels impurities (Hofmann et al 1986). This possibility seems unlikely because laboratory partitioning experiments suggest that $\mathrm{He}$ is not present in high concentrations within the Fe metal of the core (Matsuda et al 1993). Based on global correlations of He and lithophile isotopic ratios, several investigators have identified a reasonably restricted $\mathrm{Sr}-\mathrm{Nd}-\mathrm{Pb}$ isotope composition for the high ${ }^{3} \mathrm{He} /{ }^{4} \mathrm{He}$ source. Although these estimates, variously "FOZO" (Hart et al 1992), "C" (Hanan \& Graham 1996), or "PHEM" (Farley et al 1992), differ in detail, they are in general agreement that the component with high ${ }^{3} \mathrm{He} /{ }^{4} \mathrm{He}$ ratios is slightly depleted relative to bulk Earth estimates. Whether this reflects an origin from a single partially depleted and partially outgassed reservoir, or the product of some type of mixing between different reservoirs, is still at issue.

If the general view that ${ }^{3} \mathrm{He} /{ }^{4} \mathrm{He}$ ratios reflect the degree of degassing of mantle sources is correct, then there must be a positive correlation between ${ }^{3} \mathrm{He}$ concentration and ${ }^{3} \mathrm{He} /{ }^{4} \mathrm{He}$ ratio in the mantle; mantle source regions rich in primordial gases must retain more ${ }^{3} \mathrm{He}$ and have higher ${ }^{3} \mathrm{He} /{ }^{4} \mathrm{He}$ ratios. However, this does not imply that erupted lavas (or their phenocrysts) should show similar variations in He concentration. As shown in Figure 2, there is no strong correlation between He content and isotopic ratio in OIB samples. This lack of correlation almost certainly reflects the fact that noble gas concentrations are easily modified from their mantle values by magmatic degassing, partial melting, and variations in gas trapping efficiency in phenocrysts. The lack of correlation should not be taken as evidence against an important role for degassing.

Although the discussion of the MORB and high ${ }^{3} \mathrm{He} /{ }^{4} \mathrm{He}$ reservoirs is usually couched in terms of mantle degassing, several recent authors have presented evidence apparently in conflict with such an interpretation. Graham et al (1996) 
found a nearly linear relationship between ${ }^{3} \mathrm{He} /{ }^{4} \mathrm{He}$ and ${ }^{87} \mathrm{Sr} /{ }^{86} \mathrm{Sr}$ in a suite of MORBs, an observation they attributed to mixing between MORB mantle and a high ${ }^{3} \mathrm{He} /{ }^{4} \mathrm{He}$ component with very similar ${ }^{3} \mathrm{He} /{ }^{86} \mathrm{Sr}$ ratios. This observation is not obviously consistent with the prediction that the high ${ }^{3} \mathrm{He} /{ }^{4} \mathrm{He}$ mantle has much higher He concentrations than the MORB mantle. Very similar nearly linear mixing has been reported from Hawaiian volcanos (Eiler et al 1997). If the high ${ }^{3} \mathrm{He} /{ }^{4} \mathrm{He}$ mantle has far higher ${ }^{3} \mathrm{He}$ concentrations than the MORB mantle, some process must act to efficiently lower its concentration to very nearly the MORB level prior to mixing with the MORB mantle. Rather than degassing, Graham et al (1996) suggested that variations in He isotope ratio might instead reflect preferential recycling of $U$ into the upper mantle via subduction, thereby lowering its ${ }^{3} \mathrm{He} /(\mathrm{U}+\mathrm{Th})$ relative to the high ${ }^{3} \mathrm{He} /{ }^{4} \mathrm{He}$ mantle.

The low ${ }^{3} \mathrm{He} /{ }^{4} \mathrm{He}$ ratios of some mantle samples require a lower ${ }^{3} \mathrm{He} /(\mathrm{U}+\mathrm{Th})$ ratio than the high ${ }^{3} \mathrm{He}$ hotspots and than the MORB mantle, a characteristic that has been attributed to recycling of subducted crustal materials (rich in $\mathrm{U}$, $\mathrm{Th}$, poor in ${ }^{3} \mathrm{He}$ ) into the source region of these hotspots. A role for subducted materials is consistent with general views regarding the radiogenic and stable isotope heterogeneity of oceanic lavas, and indeed the lowest ${ }^{3} \mathrm{He} /{ }^{4} \mathrm{He}$ ratios occur in volcanos that also have extreme radiogenic isotope signatures (e.g. Graham et al 1992a). If crustal recycling accounts for the radiogenic isotope heterogeneity of the mantle, it is somewhat surprising that observed ${ }^{3} \mathrm{He} /{ }^{4} \mathrm{He}$ ratios are not substantially lower than has been observed. It has been suggested that the recycled materials erupted at ocean islands may have resided in the mantle for billions of years (Hofmann \& White 1982). If this material has $U$ and Th abundances typical of oceanic sediments, it will acquire extraordinarily high $\mathrm{He}$ concentrations (with ${ }^{3} \mathrm{He} /{ }^{4} \mathrm{He} \sim 0$ ) over this period. For example, a protolith with 1-ppm U and 1-ppm Th held as a closed system for $2 \mathrm{Ga}$ will accumulate more than an order of magnitude more He than is estimated for the concentration of helium in the high ${ }^{3} \mathrm{He}$ mantle, and from 25 to 360 times higher than various estimates for the MORB source (Allegre et al 1986, Porcelli \& Wasserburg 1995a). Either very little of such material is present in ocean island source regions, or the radiogenic He is largely lost from the subducted material prior to mixing with other (higher ${ }^{3} \mathrm{He} /{ }^{4} \mathrm{He}$ ) mantle materials. Alternatively, at least in some cases, the subducted material may have experienced a much shorter mantle residence (Farley 1995).

\section{Coupled Mantle-Atmosphere Evolution Models}

A primary objective of mantle noble gas geochemistry is to identify the mechanism and timing of the processes that have produced the atmosphere and to understand the origin of the geochemical structure of the Earth. Over the last 30 years, numerous investigators have developed models to describe the mantle 
degassing process through mass balance equations among mantle and atmospheric reservoirs. Early models (see Ozima \& Podosek 1983 for a review) were based on a single isotopic system (usually Ar), but more sophisticated recent models attempt to accommodate constraints from several of the noble gases. Simultaneous modeling of all the noble gases allows additional temporal information and potentially identifies the outgassing mechanism (because of variability in ingrowth time scale and geochemical behavior of the noble gases).

In following early thinking about the geochemical structure of the mantle, these models usually assume geochemically distinct upper and lower mantles whose chemical compositions are essentially homogeneous. These reservoirs are linked to the MORB (upper) mantle and the high ${ }^{3} \mathrm{He} /{ }^{4} \mathrm{He}$ (lower) mantle sampled best at Loihi Seamount. These reservoirs may be synonymous with the depleted and "primitive" or "undepleted" mantle, but this is not necessarily so (Allegre et al 1986). Such a layered two-reservoir mantle is obviously an oversimplification of the Earth, but the problem is only marginally constrained by existing data for a two reservoir mantle and it becomes seriously underconstrained when more reservoirs (whose composition is not presently known) are allowed.

Several models that attempt to simultaneously account for all of the radiogenic noble gases have been offered. The models developed by Allegre and coworkers (1986) and by Zhang \& Zindler (1989) and Azbel \& Tolstikhin (1990) assume that the upper and lower mantle reservoirs are and always have been very well isolated from each other (with the possible exception of some He exchange). The atmosphere is the complement to a degassed upper mantle, whereas the lower mantle remains relatively undegassed. In the model presented by Allegre et al (1986), the noble gases are assumed to be extracted from the mantle by a bulk degassing process, i.e. one that does not fractionate the noble gases from each other. With this assumption, observed noble gas systematics (primarily Ar and Xe isotopic ratios) can be accounted for by calling upon a two-stage outgassing process, in which a period of extremely rapid ("catastrophic") degassing occurs shortly after accretion, followed by a slowly declining degassing rate over the remainder of Earth history. In contrast, Zhang \& Zindler (1989) accounted for the same set of observations with a single-stage degassing process, but one in which the noble gases are extracted at a rate inversely proportional to their solubility. In such a model, the less soluble heavier noble gases are extracted more rapidly than the lighter noble gases via bubble formation and removal from a magma. Regardless of this detail, both models indicate that the upper mantle is extremely outgassed, probably over $98 \%$ of the primordial volatiles have been removed, and most of this removal occurred very early in Earth history. 
These models were based on data that have improved since publication of the models. For example, the ${ }^{40} \mathrm{Ar} /{ }^{36} \mathrm{Ar}$ ratio of the lower (Loihi) mantle is now clearly substantially higher than these authors assumed. This observation can be accommodated within the models fairly easily and would lead to quantitatively different but qualitatively similar results (Y Zhang, personal communication). More importantly, new Ne isotopic data require that the atmosphere has not been closed to extraterrestrial exchanges, in violation of model assumptions. If $\mathrm{Ne}$ was fractionated by hydrodynamic escape, then these models are still tenable, provided loss of $\mathrm{Ar}$ and $\mathrm{Xe}$ did not also occur, because most of the information comes from the latter gases. The models are largely untenable if the atmosphere has substantial sources other than degassing of the solid Earth.

A fundamentally different approach has been suggested by O'Nions \& Tolstikhin (1994) and explored in detail by Porcelli \& Wasserburg (1995a, 1995b). Following ideas developed for $\mathrm{Pb}$ (Galer \& O'Nions 1985) and $\mathrm{He}$ (Kellogg \& Wasserburg 1990) isotope systematics of the upper mantle, these authors considered a lower mantle that is largely undegassed and an upper mantle that is in steady state between loss via volcanism and injections from the lower mantle via plumes, from the atmosphere via subduction and from in-situ radioactive decay. In contrast to previous models, exchange between the upper and lower mantle is required. In the model of Porcelli \& Wasserburg, the noble gases are assumed to degas from the upper mantle with equal efficiency (bulk degassing), but they may be fractionated during the subduction process. The upper mantle is then a dynamic reservoir that, because it is not simply residual to the atmosphere, cannot be used to uniquely constrain the degassing history of the solid Earth. In the context of such a model, most of the radiogenic noble gases in the upper mantle are derived by in situ decay, but because ${ }^{129} I$ is extinct, the anomalies in ${ }^{129} \mathrm{Xe} /{ }^{130} \mathrm{Xe}$ ratio must be inherited from the lower mantle. Thus this model is at odds with the interpretation that Loihi Seamount samples with air-like Xe represent the lower mantle composition, and such values would have to be the product of atmospheric contamination. Furthermore, in this model there is no way for the $\mathrm{Xe}$ in the atmosphere to be derived exclusively from degassing of known solid Earth reservoirs. An addition of Xe from a source with high $\mathrm{Xe} / \mathrm{I}$ ratio (such that no ${ }^{129} \mathrm{Xe}$ anomalies are present) is required. Such xenon may have derived from late addition of cometary material.

All of these models indicate a very large concentration contrast between the degassed and undegassed reservoirs, typically on the order of 50-100 times. The available data do not obviously indicate such a contrast. For example, if the Loihi source, with a ${ }^{3} \mathrm{He} /{ }^{4} \mathrm{He}$ ratio of $30 \mathrm{R}_{\mathrm{A}}$, has 100 times more He than the MORB source, then over a large range of mixing proportions between these two sources, nearly all $\mathrm{He}$ would be derived from the high ${ }^{3} \mathrm{He} /{ }^{4} \mathrm{He}$ source. 
Thus it is surprising that so many hotspot volcanos have ${ }^{3} \mathrm{He} /{ }^{4} \mathrm{He}$ ratios that are intermediate between 30 and $8 \mathrm{R}_{\mathrm{A}}$ (Figure 2); one would instead expect to find many localities with ${ }^{3} \mathrm{He} /{ }^{4} \mathrm{He}$ ratios that are indistinguishable from the high ${ }^{3} \mathrm{He} /{ }^{4} \mathrm{He}$ endmember. Similarly, the lack of curvature in isotope ratio-isotope ratio plots involving He and the lithophile tracers (Graham et al 1996, Eiler et al 1997) is not consistent with such a large concentration contrast. It is possible that mantle plumes are stripped of a large fraction of their He prior to mixing, but such an explanation is ad hoc. Further work is needed to understand these paradoxical observations.

\section{CONCLUSIONS}

The database presently available for mantle noble gases provides a fairly clear picture of $\mathrm{He}$ isotopic variability within the mantle and a preliminary indication of the isotopic systematics of the heavier noble gases. The major uncertainty in the mantle composition remains atmospheric contamination of the heavier noble gases, and in general only limits to the mantle composition have been established. The problem is particularly severe for Xe. Future advances in characterizing heavier noble gases in the mantle will rely on either $(a)$ the discovery of unusual samples with high mantle noble gas concentrations that are comparatively immune to contamination effects [e.g. gas-rich xenoliths or OIB glasses erupted at great depth (Poreda \& Farley 1992, Valbracht et al 1997)] or (b) development of improved analytical techniques that can isolate the mantle component from the contaminant. One promising new technique for isolating mantle gases is laser extraction; apparently in some cases, mantle and atmospheric gases are spatially resolved at the millimeter to submillimeter scale and can be partially isolated using a laser microprobe (Burnard et al 1994, 1997, Farley \& Craig 1994).

The presently available data can be reasonably explained by variations in the degree of mantle degassing. Most simply, the isotopic data suggest the existence of a highly degassed MORB mantle and a less degassed reservoir sampled at some ocean islands. Intermediate compositions may represent mixtures between these two reservoirs. This conclusion is most evident from the He isotopic data and is the traditional explanation for mantle noble gas isotopic variability. The heavier noble gases can also be explained within such a framework and suggest that much of the degassing occurred very early in Earth history. However, a more detailed interpretation is hindered by uncertainties regarding the degree of atmospheric contamination present in samples and by poor knowledge of the mechanism that has extracted gases from the Earth and of the geochemical behavior of noble gases. The apparent lack of extreme concentration contrast between the supposed "degassed" and "less degassed" sources is surprising and 
may indicate that alternative explanations are necessary. Further progress in this area will require simultaneous consideration of noble gases and lithophile element isotope ratios and their relevant parent/daughter geochemical behavior, strongly coupled to mantle geodynamic models.

The origins of the atmosphere and of the primordial gases accreted within the Earth are critical to interpretations of the geochemical evolution of the Earth system. High ${ }^{20} \mathrm{Ne} /{ }^{22} \mathrm{Ne}$ ratios in mantle samples and the success of the model developed by Honda and coworkers for rationalizing mantle $\mathrm{He}-\mathrm{Ne}$ isotopic systematics by assuming solar-like $\mathrm{He}$ isotope and $\mathrm{He} / \mathrm{Ne}$ ratios provide strong evidence for a solar-like source for gases in the solid Earth. However, the composition of $\mathrm{Ne}$ in the atmosphere is clearly not solar-like, requiring either a different source for the atmosphere or mass fractionating escape of $\mathrm{Ne}$ from the early atmosphere. The recent suggestion of solar-like $\mathrm{Xe}$ in $\mathrm{CO}_{2}$ well gases (Cafee et al 1988), if confirmed for the mantle in general, would have serious implications for this debate because it would become increasingly difficult to fractionate the atmosphere in the appropriate way. The origin of the atmosphere remains a critical and still unresolved question.

\title{
ACKNOWLEDGMENTS
}

We thank D Graham, D Hilton, D Porcelli, and D Patterson for helpful comments.

\author{
Visit the Annual Reviews home page at \\ http://www.AnnualReviews.org.
}

Literature Cited

Allegre CJ, Moreira M, Staudacher T. 1995. ${ }^{4} \mathrm{He} /{ }^{3} \mathrm{He}$ dispersion and mantle convection. Geophys. Res. Lett. 22:2325-28

Allegre CJ, Sarda P, Staudacher T. 1993. Speculations about cosmic origin of $\mathrm{He}$ and $\mathrm{Ne}$ in the interior of the Earth. Earth Planet. Sci. Lett. 117:229-33

Allegre CJ, Staudacher T, Sarda P. 1986. Rare gas systematics: formation of the atmosphere, evolution and structure of the Earth's mantle. Earth Planet. Sci. Lett. 81:127-50

Allegre CJ, Staudacher T, Sarda P, Kurz M. 1983. Constraints on evolution of Earth's mantle from rare gas systematics. Nature 303: 762-66

Anderson DL. 1993. ${ }^{3} \mathrm{He}$ from the mantle: primordial signals or cosmic dust? Science 261:170-74

Azbel IY, Tolstikhin IN. 1990. Geodynamics, magmatism, and degassing of the Earth. Geochim. Cosmochim. Acta 54:139-54
Broadhurst CL, Drake MJ, Hagee BE, Bernatowicz TJ. 1992. Solubility and partitioning of $\mathrm{Ne}, \mathrm{Ar}, \mathrm{Kr}$, and $\mathrm{Xe}$ in minerals and synthetic basaltic melts. Geochim. Cosmochim. Acta 56:709-23

Brown H. 1952. Rare gases and formation of the Earth's atmosphere. In The Atmospheres of the Earth and Planets, ed. GP Kuiper, pp. 258-66. Chicago: Univ. Chicago Press

Burnard P, Graham D, Turner G. 1997. Vesiclespecific noble gas analyses of "popping rock"; implications for primordial noble gases in the Earth. Science 276:568-71

Burnard PG, Stuart FM, Turner G, Oskarsson N. 1994. Air contamination of basaltic magmas: implications for high ${ }^{3} \mathrm{He} /{ }^{4} \mathrm{He}$ mantle Ar isotopic composition. J. Geophys. Res. 99:17709-15

Cafee M, Hudson G, Velsko C, Alexander E, Huss G, Chivas A. 1988. Non-atmospheric noble gases from $\mathrm{CO}_{2}$ well gases. Proc. 
Lunar Planet. Sci. 19:154-55

Carroll MR, Draper DS. 1994. Noble gases as trace elements in magmatic processes. Chem. Geol. 117:37-56

Clarke WB, Beg MA, Craig H. 1969. Excess $\mathrm{He}-3$ in the sea: evidence for terrestrial primordial helium. Earth Planet. Sci. Lett. 6:213-21

Condomines M, Gronvold K, Hooker PJ, Muehlenbachs K, O’Nions RK, et al. 1983. Helium, oxygen, strontium and neodymium isotopic relationships in Icelandic volcanics. Earth Planet. Sci. Lett. 66:125-36

Craig H. 1990. Helium isotope distribution in mantle hotspots. Eos, Trans. Am. Geophys. Union 71:1669

Craig H, Lupton JE. 1976. Primordial neon, helium and hydrogen in oceanic basalts. Earth Planet. Sci. Lett. 31:369-85

Eiler J, Farley K, Stolper E. 1997. Correlated He and $\mathrm{Pb}$ isotopic variations in Hawaiian lavas. Geochim. Cosmochim. Acta. Submitted

Farley KA. 1995. Rapid cycling of subducted sediments into the Samoan mantle plume. Geology 23:531-34

Farley KA, Basu AR, Craig H. 1993. He, Sr, and $\mathrm{Nd}$ isotopic variations in lavas from the Juan Fernandez Archipelago, SE Pacific. Contrib. Mineral. Petrol. 115:75-87

Farley KA, Basu AR, Nilsson K. 1991. Geochemistry and isotopic composition of Guadalupe Island lavas and ultramafic xenoliths. Eos, Trans. Am. Geophys. Union 72:500

Farley KA, Craig H. 1994. Atmospheric argon contamination of ocean island basalt olivine phenocrysts. Geochim. Cosmochim. Acta 58:2509-17

Farley KA, Natland JH, Craig H. 1992. Binary mixing of enriched and undegassed (primitive?) mantle components ( $\mathrm{He}, \mathrm{Sr}, \mathrm{Nd}, \mathrm{Pb}$ ) in Samoan lavas. Earth Planet. Sci. Lett. 111:183-99

Farley KA, Poreda RJ. 1993. Mantle neon and atmospheric contamination. Earth Planet. Sci. Lett. 114:325-39

Fisher DE. 1983. Rare gases from the undepleted mantle? Nature 305:298-300

Galer SJG, O'Nions RK. 1985. Residence time of thorium, uranium and lead in the mantle with implications for mantle convection. $\mathrm{Na}$ ture 316:778-82

Garcia MO, Kurz MD, Muenow DW. 1990. Mahukona, the missing Hawaiian volcano. Geology 18:1111-14

Gerlach T. 1989. Degassing of carbon dioxide from basaltic magma at spreading centers: II. Mid-ocean ridge basalts. J. Volc. Geotherm. Res. 39:221-32

Graham D, Lupton J, Albarede F, Condomies M. 1990. Extreme temporal homogeneity of helium isotopes at Piton de la Fournaise, Re- union Island. Nature 347:545-48

Graham DW, Castillo PR, Lupton JE, Batiza R. 1996. Correlated $\mathrm{He}$ and $\mathrm{Sr}$ isotope ratios in south Atlantic near-ridge seamounts and implications for mantle dynamics. Earth Planet. Sci. Lett. 144:491-503

Graham DW, Christie DM, Harpp KS, Lupton JE. 1993. Mantle plume helium in submarine basalts from the Galapagos platform. Science 262:2023-26

Graham DW, Humphris SE, Jenkins WJ, Kurz MD. 1992a. Helium isotope geochemistry of some volcanic rocks from St. Helena. Earth Planet. Sci. Lett. 110:121-32

Graham DW, Jenkins WJ, Schilling JG, Thompson G, Kurz MD, Humphris SE. 1992b. Helium isotope geochemistry of mid-ocean ridge basalts from the South Atlantic. Earth Planet. Sci. Lett. 110:133-48

Hanan B, Graham D, Michael P, Schilling JG. 1992. He and $\mathrm{Pb}$ isotope constraints for the origin of a short wavelength geochemical anomaly along the South Atlantic midocean ridge. Eos, Trans. Am. Geophys. Union 73:582

Hanan BB, Graham DW. 1996. Lead and helium isotope evidence from oceanic basalts for a common deep source of mantle plumes. Science 272:991-95

Hart SR, Hauri EH, Oschmann LA, Whitehead JA. 1992. Mantle plumes and entrainment: isotopic evidence. Science 256:517-20

Hilton DR, Barling J, Wheller GE. 1995. Effect of shallow level contamination on the helium isotope systematics of ocean-island lavas. Nature 373:330-33

Hiyagon H. 1994. Retention of solar helium and neon in IDPs in deep sea sediments. Science 263:1257-59

Hiyagon H, Ozima M. 1986. Partition of noble gases between olivine and basalt melt. Geochim. Cosmochim. Acta 50:2045-57

Hiyagon H, Ozima M, Marty B, Zashu S, Sakai H. 1992. Noble gases in submarine glasses from mid-oceanic ridges and Loihi Seamount: constraints on the early history of the Earth. Geochim. Cosmochim. Acta 56: 1301-16

Hofmann AW, Jochum KP, Seufert M, White WM. 1986. $\mathrm{Nb}$ and $\mathrm{Pb}$ in oceanic basalts: new constraints on mantle evolution. Earth Planet. Sci. Lett. 79:33-45

Hofmann AW, White WM. 1982. Mantle plumes from ancient oceanic crust. Earth Planet. Sci. Lett. 57:421-36

Honda M, McDougall I. 1997. Primordial helium and neon in the Earth: a speculation on early degassing. In 7th Annu. V.M. Goldschmidt Conf., Lunar Planet. Inst. Contrib. 921, p. 98. Houston: Lunar Planet. Inst.

Honda M, McDougall I, Patterson D, Doulgeris 
A, Clague D. 1991. Possible solar noblegas component in Hawaiian basalts. Nature 349:149-51

Honda M, McDougall I, Patterson DB, Doulgeris A, Clague D. 1993. Noble gases in submarine pillow basalt glasses from Loihi and Kileaua, Hawaii: a solar component in the Earth. Geochim. Cosmochim. Acta 57:85974

Honda M, Reynolds JH, Roedder E, Epstein S. 1987. Noble gases in diamonds: occurrences of solarlike helium and neon. J. Geophys. Res. 92:12507-21

Hudson G, Kennedy B, Podosek F, Hohenberg C. 1988. The early Solar System abundance of ${ }^{244} \mathrm{Pu}$ as inferred from the St. Severin chondrite. Proc. Lunar Planet. Sci. 19:547-57

Hünemohr H. 1989. Edelgase in U- und Threichen Mineralen und die Bestimmung der ${ }^{21} \mathrm{Ne}$-Dicktarget-Ausbeute $\mathrm{der}^{18} \mathrm{O}(\alpha \cdot n)^{21} \mathrm{Ne}$ Kernreaktion im Bereich 4.0-8.8 MeV. $\mathrm{PhD}$ thesis. Max Planck Inst., Mainz

Hunten DM, Pepin RO, Walker JCG. 1987. Mass fractionation in hydrodynamic escape. Icarus 69:532-49

Jambon A, Weber H, Braun O. 1986. Solubility of $\mathrm{He}, \mathrm{Ne}, \mathrm{Ar}, \mathrm{Kr}$ and $\mathrm{Xe}$ in a basalt melt in the range $1250-1600^{\circ} \mathrm{C}$. Geochemical implications. Geochim. Cosmochim. Acta 50:4018

Jambon A, Weber HW, Begemann F. 1985. Helium and argon from an Atlantic MORB glass: concentration, distribution and isotopic composition. Earth Planet. Sci. Lett. 73:255-67

Jochum KP, Hofmann AW, Ito E, Seufert HM, White WM. 1983. K, U and Th in mid-ocean ridge basalt glasses and heat production, $\mathrm{K} / \mathrm{U}$ and $\mathrm{K} / \mathrm{Rb}$ in the mantle. Nature 306:431-36

Kaneoka I, Takaoka N, Clague DA. 1983. Noble gas systematics for coexisting glass and olivine crystals in basalts and dunite xenoliths from Loihi Seamount. Earth Planet. Sci. Lett. 66:427-37

Kaneoka I, Takaoka N, Upton BGJ. 1986. Noble gas systematics in basalts and a dunite nodule from Reunion and Grand Comore Islands, Indian Ocean. Chem. Geol. 59:35-42

Kellogg LH, Wasserburg GJ. 1990. The role of plumes in mantle helium fluxes. Earth Planet. Sci. Lett. 99:276-89

Kurz MD, Garcia MO, Frey FA, O'Brien PA. 1987. Temporal helium isotopic variations within Hawaiian volcanoes: basalts from Mauna Loa and Haleakala. Geochim. Cosmochim. Acta 51:2905-14

Kurz MD, Jenkins WJ, Hart SR. 1982. Helium isotopic systematics of oceanic islands and mantle heterogeneity. Nature 297:43-46

Kurz MD, Jenkins WJ, Hart SR, Clague D. 1983. Helium isotopic variations in volcanic rocks from Loihi Seamount and the island of Hawaii. Earth Planet. Sci. Lett. 66:388-99

Kurz MD, Kammer DP. 1991. Isotopic evolution of Mauna Loa Volcano. Earth Planet. Sci. Lett. 103:257-69

Kurz MD, Kenna TC, Lassiter JC, Depaolo DJ. 1996. Helium isotopic evolution of Mauna Kea volcano - first results from the $1 \mathrm{~km}$ drill core. J. Geophys. Res. 101:11781-91

Kurz MD, Meyer PS, Sigurdsson H. 1985. Helium isotopic systematics within the neovolcanic zones of Iceland. Earth Planet. Sci. Lett. 74:291-305

Kurz MD, Moore RB, Kammer DP, Gulesserian A. 1997. An isotopic study of dated alkali basalts from Sao Miguel, Azores: implications for the origin of the Azores hotspot. Earth Planet. Sci. Lett. Submitted

Kyser TK, Rison W. 1982. Systematics of rare gas isotopes in basic lavas and ultramafic xenoliths. J. Geophys. Res. 87:5611-30

Lux G. 1987. The behavior of noble gases in silicate liquids: solution, diffusion, bubbles and surface effects, with applications to natural samples. Geochim. Cosmochim. Acta 51:1549-60

Mahoney JJ, Sinton JM, Kurz MD, Macdougall JD, Spencer KJ, Lugmair GW. 1994. Isotope and trace element characteristics of a superfast spreading ridge: East Pacific Rise, 13$23^{\circ}$ S. Earth Planet. Sci. Lett. 121:173-93

Mamyrin BA, Tolstikhin IN, Anufriev GS, Kamenskii IL. 1969. Anomalous isotopic composition of helium in volcanic gases. Dokladay 184:1994-97

Marty B. 1989. Neon and xenon isotopes in MORB: implications for the Earth-atmosphere evolution. Earth Planet. Sci. Lett. 94:45-56

Marty B, Lussiez P. 1993. Constraints on rare gas partition coefficients from analysis of olivine-glass from a picritic mid-ocean ridge basalt. Chem. Geol. 106:1-7

Marty B, Zashu S, Ozima M. 1983. Two noble gas components in a Mid-Atlantic Ridge basalt. Nature 302:238-40

Matsuda J, Sudo M, Ozima M, Ito K, Ohtaka O, Ito E. 1993. Noble gas partition between metal and silicate under high pressures. Science 259:788-90

Menzies MA, Hawkesworth CJ. 1987. Mantle Metasomatism. London: Academic. 472 pp.

Merrihue C. 1964. Rare gas evidence for cosmic dust in modern Pacific red clay. Ann. NY Acad. Sci. 119:351-67

Moreira M, Kunz J, Allegre C. 1997. Rare gas systematics in the upper mantle: a complete study of a popping rock. In 7th Annu. V.M. Goldschmidt Conf., Lunar Planet. Inst. Contrib. 921, p. 144. Houston: Lunar Planet. Inst. Moreira M, Staudacher T, Sarda P, Schilling 
J-G, Allegre CJ. 1995. A primitive plume neon component in MORB: the Shona ridgeanomaly, South Atlantic (51-52 S). Earth Planet. Sci. Lett. 133:367-77

Mukhopadhyay S, Farley K, Bogue S. 1996. Loihi-like ${ }^{3} \mathrm{He} /{ }^{4} \mathrm{He}$ ratios in shield and caldera-filling lavas from Kauai. Eos, Trans. Am. Geophys. Union 77:F811

O'Nions R, Tolstikhin I. 1994. Behavior and residence times of lithophile and rare gas tracers in the upper mantle. Earth Planet. Sci. Lett. 124:131-38

Ozima M. 1994. Noble gas state in the mantle. Rev. Geophys. 32:405-26

Ozima M, Azuma S, Zashu S, Hiyagon H. 1993. ${ }^{244} \mathrm{Pu}$ fission $\mathrm{Xe}$ in the mantle and mantle degassing chronology. In Primitive Solar Nebula and Origin of Planets, ed. H Oya, pp. 503-17. Tokyo: Terra

Ozima M, Podosek FA. 1983. Noble Gas Geochemistry. Cambridge: Cambridge Univ. Press. 367 pp.

Ozima M, Podosek FA, Igarashi G. 1985. Terrestrial xenon isotope constraints on the early history of the Earth. Nature 315:471-74

Ozima M, Zashu S. 1988. Solar-type neon in Zaire cubic diamonds. Geochim. Cosmochim. Acta 52:19-25

Ozima M, Zashu S. 1991. Noble gas state of the ancient mantle as deduced from noble gases in coated diamonds. Earth Planet. Sci. Lett. 105:13-27

Patterson DB, Honda M, McDougall I. 1990. Atmospheric contamination: a possible source for heavy noble gases in basalts from Loihi Seamount, Hawaii. Geophys. Res. Lett. 17:705-8

Patterson DB, Honda M, McDougall I. 1994. Deconvolution of multiple components of neon and helium in mantle-derived samples. In Noble Gas Geochemistry and Cosmochemistry, ed. J Matsuda, pp. 179-89. Tokyo: Terra

Phinney D, Tennyson J, Frick U. 1978. Xenon in $\mathrm{CO}_{2}$ well gas revisited. J. Geophys. Res. 83:2313-19

Porcelli D, Wasserburg GJ. 1995a. Mass transfer of helium, neon, argon, and xenon through a steady-state upper mantle. Geochim. Cosmochim. Acta 59:4921-37

Porcelli D, Wasserburg GJ. 1995b. Mass transfer of xenon through a steady-state upper mantle. Geochim. Cosmochim. Acta 59: 1191-2007

Poreda R, Radicati di Brozolo F. 1984. Neon isotope variations in Mid-Atlantic ridge basalts. Earth Planet. Sci. Lett. 69:277-89

Poreda R, Schilling J-G, Craig H. 1986. Helium and hydrogen isotopes in ocean ridge basalts north and south of Iceland. Earth Planet. Sci. Lett. 78:1-17
Poreda RJ, Farley KA. 1992. Rare gases in Samoan xenoliths. Earth Planet. Sci. Lett. 113:129-44

Poreda RJ, Schilling J-G, Craig H. 1993. Helium isotope ratios in Easter microplate basalts. Earth Planet. Sci. Lett. 119:319-29

Rison W, Craig H. 1983. Helium isotopes and mantle volatiles in Loihi Seamount and Hawaiian Island basalts and xenoliths. Earth Planet. Sci. Lett. 66:407-26

Roden M, Trull T, Hart S, Frey F. 1994. New $\mathrm{He}, \mathrm{Nd}, \mathrm{Pb}$, and $\mathrm{Sr}$ isotopic constraints on the constitution of the Hawaiian plume - results from Koolau Volcano, Oahu, Hawaii, USA. Geochim. Cosmochim. Acta 58:143140

Sarda P, Graham D. 1990. Mid-ocean ridge popping rocks: implications for degassing at ridgecrests. Earth Planet. Sci. Lett. 97:26889

Sarda P, Staudacher T, Allegre CJ. 1985. ${ }^{40} \mathrm{Ar} /{ }^{36} \mathrm{Ar}$ in MORB glasses: constraints on atmosphere and mantle evolution. Earth Planet. Sci. Lett. 72:357-75

Sarda P, Staudacher T, Allegre CJ. 1988. Neon isotopes in submarine basalts. Earth Planet. Sci. Lett. 91:73-88

Staudacher T. 1987. Upper mantle origin for Harding County well gases. Nature 325:6057

Staudacher T, Allegre CJ. 1982. Terrestrial xenology. Earth Planet. Sci. Lett. 60:389406

Staudacher T, Allegre CJ. 1988. Recycling of oceanic crust and sediments: the noble gas subduction barrier. Earth Planet. Sci. Lett. 89:173-83

Staudacher T, Allegre CJ. 1989. Noble gases in glass samples from Tahiti: Teahitia, Rocard, and Mehetia. Earth Planet. Sci. Lett. 93:21022

Staudacher T, Kurz MD, Allegre CJ. 1986. New noble gas data on glass samples from Loihi Seamount and Hualalai and on dunite samples from Loihi and Reunion Island. Chem. Geol. 56:193-205

Staudacher T, Sarda P, Allegre CJ. 1990. Noble gas systematics of Reunion Island, Indian Ocean. Chem. Geol. 89:1-17

Staudacher T, Sarda P, Richardson SH, Allegre CJ, Sogna I, Dmitriev LV. 1989. Noble gases in basalt glasses from a mid-atlantic ridge topographic high at $14^{\circ} \mathrm{N}$ : geodynamic consequences. Earth Planet. Sci. Lett. 96:119-33

Tatsumoto M, Nakamura Y, Basu A, Craig H. 1990. U-Th- $\mathrm{Pb}$ and He isotopic variations in volcanic rocks from the Hawaiian and CookAustral chains. Eos, Trans. Am. Geophys. Union 71:850

Trull T. 1994. Influx and age constraints on the recycled cosmic dust explanation for high 
${ }^{3} \mathrm{He} /{ }^{4} \mathrm{He}$ ratios at hotspot volcanos. In Noble Gas Geochemistry and Cosmochemistry, ed. J Matsuda, pp. 77-88. Tokyo: Terra

Valbracht P, Honda M, Matsumoto T, Mattielli N, McDougall I. 1996. Helium, neon and argon isotope systematics in Kerguelen ultramafic xenoliths - implications for mantle source signatures. Earth Planet. Sci. Lett. 138:29-38

Valbracht P, Staudacher T, Malahoff A, Moreira M, Allegre C. 1997. Noble gas systematics of deep rift zone glasses from Loihi Seamount, Hawaii. Earth Planet. Sci. Lett. In press

Valbracht PJ, Staudigel H, Honda M, McDougall I, Davies GR. 1995. Isotopic tracing of volcanic source regions from Hawaii: decoupling of gaseous from lithophile magma components. Earth Planet. Sci. Lett. 144: 185-98

Vance D, Stone JOH, O’Nions RK. 1989. He, $\mathrm{Sr}$ and $\mathrm{Nd}$ isotopes in xenoliths from Hawaii and other oceanic islands. Earth Planet. Sci. Lett. 96:147-69

Wetherill G. 1954. Variations in the isotopic abundances of neon and argon extracted from radioactive minerals. Phys. Rev. 96:679-83

Wolfe C, Bjarnason I, Vandecar J, Solomon S. 1997. Seismic structure of the Iceland mantle plume. Nature 385:245-47

Yatsevich I, Honda M. 1997. Production of nucleogenic neon in the Earth from natural radioactive decay. J. Geophys. Res. 102:1029198

Zahnle K, Kasting J, Pollack J. 1990. Mass fractionation of noble gases in diffusionlimited hydrodynamic hydrogen escape. Icarus 84:502-27

Zhang Y, Zindler A. 1989. Noble gas constraints on the evolution of the Earth's atmosphere. $J$. Geophys. Res. 94:13719-37

Zindler A, Hart SR. 1986. Chemical geodynamics. Annu. Rev. Earth Planet. Sci. 14:493571 
1 Annual Review of Earth and Planetary Science

\section{CONTENTS}

Contemplation of Things Past, George W. Wetherill 1

Volcanism and Tectonics on Venus, F. Nimmo, D. McKenzie 23

TEMPERATURES IN PROTOPLANETARY DISKS, Alan P. Boss 53

THE IMPORTANCE OF PAHOEHOE, S. Self, L. Keszthelyi, Th.

Thordarson

81

CHINESE LOESS AND THE PALEOMONSOON, Tungsheng Liu, Zhongli Ding

STELLAR NUCLEOSYNTHESIS AND THE ISOTOPIC COMPOSITION OF PRESOLAR GRAINS FROM PRIMITIVE

METEORITES, Ernst Zinner

NOBLE GASES IN THE EARTH'S MANTLE, K. A. Farley, E. Neroda

SATELLITE ALTIMETRY, THE MARINE GEOID, AND THE

OCEANIC GENERAL CIRCULATION, Carl Wunsch, Detlef Stammer

CHEMICALLY REACTIVE FLUID FLOW DURING

METAMORPHISM, John M. Ferry, Martha L. Gerdes

CHANNEL NETWORKS, Andrea Rinaldo, Ignacio Rodriguez-Iturbe, Riccardo Rigon

EARLY HISTORY OF ARTHROPOD AND VASCULAR PLANT

ASSOCIATIONS, Conrad C. Labandeira

329

Ecological Aspects of the Cretaceous Flowering Plant Radiation, Scott $L$.

Wing, Lisa D. Boucher

379

The Re-Os Isotope System in Cosmochemistry and High-Temperature

Geochemistry, Steven B. Shirey, Richard J. Walker

423

DYNAMICS OF ANGULAR MOMENTUM IN THE EARTH'S CORE, Jeremy Bloxham

FISSION TRACK ANALYSIS AND ITS APPLICATIONS TO

GEOLOGICAL PROBLEMS, Kerry Gallagher, Roderick Brown,

Christopher Johnson

Isotopic Reconstruction of the Past Continental Environments, Paul L. Koch

The Plate Tectonic Approximation: Plate Nonrigidity, Diffuse Plate

Boundaries, and Global Plate Reconstructions, Richard G. Gordon

615

LABORATORY-DERIVED FRICTION LAWS AND THEIR APPLICATION TO SEISMIC FAULTING, Chris Marone 